\title{
Brassinosteroid overproduction improves lignocellulose quantity and quality to maximize bioethanol yield under green-like biomass process in transgenic poplar
}

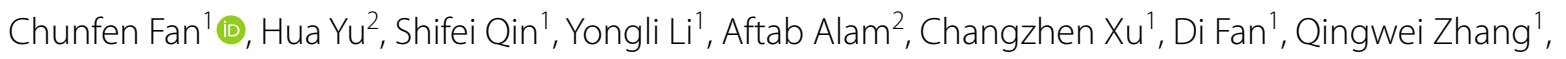
Yanting Wang ${ }^{2}$, Wanbin Zhu ${ }^{3}$, Liangcai Peng ${ }^{2,3^{*}}$ and Keming Luo ${ }^{1^{*}}$

\begin{abstract}
Background: As a leading biomass feedstock, poplar plants provide enormous lignocellulose resource convertible for biofuels and bio-chemicals. However, lignocellulose recalcitrance particularly in wood plants, basically causes a costly bioethanol production unacceptable for commercial marketing with potential secondary pollution to the environment. Therefore, it becomes important to reduce lignocellulose recalcitrance by genetic modification of plant cell walls, and meanwhile to establish advanced biomass process technology in woody plants. Brassinosteroids, plantspecific steroid hormones, are considered to participate in plant growth and development for biomass production, but little has been reported about brassinosteroids roles in plant cell wall assembly and modification. In this study, we generated transgenic poplar plant that overexpressed DEETIOLATED2 gene for brassinosteroids overproduction. We then detected cell wall feature alteration and examined biomass enzymatic saccharification for bioethanol production under various chemical pretreatments.

Results: Compared with wild type, the PtoDET2 overexpressed transgenic plants contained much higher brassinosteroids levels. The transgenic poplar also exhibited significantly enhanced plant growth rate and biomass yield by increasing xylem development and cell wall polymer deposition. Meanwhile, the transgenic plants showed significantly improved lignocellulose features such as reduced cellulose crystalline index and degree of polymerization values and decreased hemicellulose xylose/arabinose ratio for raised biomass porosity and accessibility, which led to integrated enhancement on biomass enzymatic saccharification and bioethanol yield under various chemical pretreatments. In contrast, the CRISPR/Cas9-generated mutation of PtoDET2 showed significantly lower brassinosteroids level for reduced biomass saccharification and bioethanol yield, compared to the wild type. Notably, the optimal green-like pretreatment could even achieve the highest bioethanol yield by effective lignin extraction in the transgenic plant. Hence, this study proposed a mechanistic model elucidating how brassinosteroid regulates cell
\end{abstract}

\footnotetext{
*Correspondence: Ipeng@mail.hzau.edu.cn; kemingl@swu.edu.cn

${ }^{1}$ Chongqing Key Laboratory of Plant Resource Conservation

and Germplasm Innovation, Key Laboratory of Eco-environments of Three

Gorges Reservoir Region, Ministry of Education, Institute of Resources

Botany, School of Life Sciences, Southwest University, Chongqing 400715,

China

${ }^{2}$ Biomass \& Bioenergy Research Centre, College of Plant Science \&

Technology, Huazhong Agricultural University, Wuhan 430070, China

Full list of author information is available at the end of the article
}

(c) The Author(s) 2020. This article is licensed under a Creative Commons Attribution 4.0 International License, which permits use, sharing, adaptation, distribution and reproduction in any medium or format, as long as you give appropriate credit to the original author(s) and the source, provide a link to the Creative Commons licence, and indicate if changes were made. The images or other third party material in this article are included in the article's Creative Commons licence, unless indicated otherwise in a credit line to the material. If material is not included in the article's Creative Commons licence and your intended use is not permitted by statutory regulation or exceeds the permitted use, you will need to obtain permission directly from the copyright holder. To view a copy of this licence, visit http://creativeco mmons.org/licenses/by/4.0/. The Creative Commons Public Domain Dedication waiver (http://creativecommons.org/publicdomain/ zero/1.0/) applies to the data made available in this article, unless otherwise stated in a credit line to the data. 
wall modification for reduced lignocellulose recalcitrance and increased biomass porosity and accessibility for high bioethanol production.

Conclusions: This study has demonstrated a powerful strategy to enhance cellulosic bioethanol production by regulating brassinosteroid biosynthesis for reducing lignocellulose recalcitrance in the transgenic poplar plants. It has also provided a green-like process for biomass pretreatment and enzymatic saccharification in poplar and beyond.

Keywords: Populus, Brassinosteroid, Bioethanol, Saccharification, Xylem differentiation, Lignocellulose modification, Green-like pretreatment

\section{Background}

As the main components of agricultural and forestry waste, lignocellulose represents enormous biomass resource for biofuels and biochemical production [1, 2]. Although agricultural residues and dedicated energy crops provide a large amount of lignocellulose for cellulosic ethanol production, woody biomass (softwood and hardwood) cannot be ignored to be a very important feedstock, for example, woody biomass occupies approximately $30 \%$ of total biomass in the US [3]. Woody biomass has nearly no ash and lower content of pentoses [4], which reduces transportation and processing cost and is conducive to the bioconversion to produce ethanol, and woody biomass can be harvested all year round to make long-term storage unnecessary $[4,5]$. However, compared with grasses, woody plants have higher lignin content because of their growth behavior of becoming physically larger and stronger. This makes woody biomass, particularly that from softwood species, more recalcitrant to microbial and enzymatic hydrolysis, further leading to an unacceptable cost for using woody biomass as biofuels [6]. Therefore, overcoming the recalcitrance of woody biomass is promising in biofuel production.

Lignocellulose recalcitrance is fundamentally determined by plant cell wall composition, cell wall polymer features and cell wall structure [7, 8]. Plant cell walls are composed mainly of cellulose, hemicelluloses, and lignin. Cellulose consists of $\beta-1,4$-glucan chains that form microfibrils with crystalline and amorphous regions. Cellulose crystalline index ( $\mathrm{CrI})$ and degree of polymerization (DP) are well demonstrated as the key negative factors accounting for biomass enzymatic digestibility [9-11]. In contrast, the arabinose (Ara) substitution degree of hemicelluloses in grasses has positive influence on biomass enzymatic saccharification by reducing the cellulose crystallinity $[11,12]$. Lignin typically has a negative impact on biomass enzymatic digestibility under various chemical pretreatments. However, recent findings have suggested that lignin could enhance biomass yield and lignocellulose enzymatic digestion $[12,13]$. Lignin is thus considered to play dual roles in lignocellulose digestion, depending on distinct monomer proportions. The non-specific binding of cellulases to lignin negatively impacts process economics through deactivating enzyme activities during hydrolysis [13, 14]. Additionally, biomass porosity and cellulose accessibility act as the potentially positive factors accounting for biomass saccharification of lignocellulose residues after chemical pretreatments $[15,16]$. Hence, genetic improvement of lignocellulose features could lead to significantly enhanced enzymatic saccharification of biomass and bioethanol yield [8, 16-20].

For cellulosic ethanol production, initial biomass pretreatments are considered as crucial step for enhancing sequential enzymatic hydrolysis and final yeast fermentation [1, 21-23]. Over the past years, various chemical pretreatments have been performed to reduce lignocellulose recalcitrance in grasses, such as $\mathrm{H}_{2} \mathrm{SO}_{4}, \mathrm{NaOH}$, $\mathrm{CaO}, \mathrm{Na}_{2} \mathrm{~S}+\mathrm{Na}_{2} \mathrm{CO}_{3}$ [24-29]. Acids and alkalis $\left(\mathrm{H}_{2} \mathrm{SO}_{4}\right.$ and $\mathrm{NaOH}$ ) are the classical agents applied for pretreatment to enhance biomass enzymatic hydrolysis in woody plants, but these methods release wastes and cause serious secondary environmental pollution. Therefore, it is essential to find out an optimal biomass process technology for efficient enzymatic hydrolysis with less secondary pollution release in woody plants.

In woody plants, xylem is the main component of stem. Xylem development is a complex process controlled by a network for the coordinating regulation of several diverse metabolic pathways [30]. Brassinosteroids (BRs), plant-specific steroid hormones, are considered to participate in xylem development [31]. Initially, the BRs are biosynthesized from campesterol (CR) via the early C-6 and late C- 6 oxidation pathways. For the early C- 6 oxidation pathway, campestanol $(\mathrm{CN})$ is converted to 6-oxocampestanol (6-oxoCN) and then to cathasterone (CT), teasterone (TE), 3-dehydroteaserone (3DT), typhasterol (TY), and castasterone (CS), respectively. In the late C-6 oxidation pathway, $\mathrm{CN}$ is chiefly to form 6-deoxocathasterone (6-deoxoCT) and then converted to corresponding intermediates similar to those in the early $\mathrm{C}-6$ oxidation pathway, but in a C-6 deoxy forms. A CN-independent pathway, C-22 oxidation branch, is demonstrated to occur alongside the previously reported $\mathrm{CR}$ to $\mathrm{CN}$ pathway, and suggested to be the dominant upstream BR biosynthesis pathway [32]. In these pathways, a series of enzymes have 
been characterized: DWARF4 (DWF4), CONSTITUTIVE PHOTOMORPHOGENESIS AND DWARFISM (CPD), DEETIOLATED2 (DET2), ROTUNDFOLIA3 (ROT3/CYP), and BR-6-oxidase1 (BR6ox1/2) [32]. During the enzymatic steps, DET2 catalyzes a $5 \alpha$-reduction of multiple related sterols, and is an important rate-limiting enzyme in the BR biosynthesis pathway [32]. BRs are perceived at the plasma membrane by the receptor-like kinase BRASSINOSTEROID INSENSITIVE1 (BRI1) and ASSOCIATED-KINASE1 (BAK1). BRs binding result in the dissociation of a negative regulator, BRI1 KINASE INHIBITOR 1 (BKI1), to disassociate from BRI1, and initiate a phosphorylation cascade of BRASSINOSTEROID INSENSITIVE 2 (BIN2) kinase. BIN2 controls the stabilization and activation of BRASSINAZOLE-RESISTANT1 (BRZ1) and BR-INSENSITIVE-EMS-SUPPRESSOR 1 (BES1/BZR2), and therefore to regulate the transcription of BR-responsive target genes [31, 32]. Overexpression of BR biosynthesis or signaling genes led to more xylem formation and increased cell wall deposition [31-36]. Although increasing evidence has established the connection between BRs and wood formation, the role of BRs during cell wall polysaccharide biosynthesis and modification is not well revealed, and the effects of BRs in bioethanol production are largely unknown.

Poplar is a fast-growing and widely distributed tree species, providing most woody materials around the world. In this study, we isolated PtoDET2 from Populus tomentosa Carr., characterized its role in xylem and cell wall formation during wood development, and evaluated its effect on biomass enzymatic saccharification and bioethanol production. Meanwhile, the major cell wall polysaccharide features and biomass porosity were determined. By comparing various chemical pretreatments, we find out an optimal technique relatively economical and environment-friendly for high bioethanol production. This study also proposed a mechanism model interpreting why higher bioethanol yield was achieved in the transgenic poplar under pretreatments.

\section{Results \\ PtoDET2 overexpression improved plant growth and biomass yield in poplar}

The full-length coding sequence of PtoDET2 (Potri.016G110600.1) was cloned from cDNA of $P$. tomentosa using sequence-specific primers (Additional file 1: Tables S1 and S2). Multiple sequence alignment revealed that PtoDET2 shared high identity with PtrDET2 (97.67\%) in P. trichocarpa, PeDET2 (96.89\%) in P. euphratica (Additional file 1: Fig. S1). Using public expression profiling data (http://aspwood.popgenie.org), we found that PtoDET2 is mainly expressed in wood tissues, while accumulated lower in buds, leaves, and roots
(Fig. 1a). To verify this, we analyzed PtoDET2 expression in developing organs of $P$. tomentosa by quantitative PCR (Q-PCR). As expected, PtoDET2 was expressed strongly in the secondary cell wall-forming zone of stems, such as xylem and phloem (Fig. 1b), suggesting that PtoDET2 was tightly associated with wood development in poplar.

To investigate the function of PtoDET2 in poplar growth and development, we collected the PtoDET2overexpressed (OE) and -knockout (KO) mutant lines using the CRISPR/Cas9-based genome editing system. Five independent PtoDET2-OE lines were obtained with relatively higher PtoDET2 gene expression levels, compared to the WT (Additional file 1: Fig. S2A-C). The phenotypes of OE lines showed a significantly positive correlation with the PtoDET2 gene expression levels, in which, OE-L1, L5 were regenerated based on higher PtoDET2 expression levels. More than 10 putative PtoDET2$\mathrm{KO}$ transgenic plants were generated and sequenced. Two PtoDET2 loss-of-function mutants (L11, L17), which were translational frame-shift or premature termination with insertions and deletions in three sgRNA-targeted sites, were regenerated for further analysis (Additional file 1: Fig. S2D-E). All the regenerated transgenic lines (more than 10 plans for each line) exhibited consistently phenotypes with the primary generation.

Because the PtoDET2 encodes an essential enzyme involved in brassinosteroids (BRs) biosynthesis, this study determined endogenous BRs contents. As a result, BRs levels were significantly elevated in the stems of PtoDET2-OE transgenic poplars, while decreased in PtoDET2-KO lines at $P<0.01$ level, compared with control (Fig. 1c). Meanwhile, we detected three major genes (PtoCPD, PtoROT3, PtoCYP85A2) expression, which are responding to the BRs biosynthesis in the downstream steps [33], and all three genes were significantly up-regulated in PtoDET2-OE lines, but down-regulated in PtoDET-KO lines (Fig. 1d), consistent with the altered BRs levels.

BRs are the plant-specific steroid hormones that dynamically regulate plant growth and development [30-36]. In this study, we observed a fast growth and development with more internodes and larger leaves in the PtoDET2-OE transgenic lines (Fig. 2a). Notably, during the 6-month period of growth, the PtoDET2-OE lines maintained much enhanced growth compared to the WT, including increased plant height by $17-25 \%$ and raised stem diameter by $35-48 \%$, leading to total aerial dry biomass elevated by $43-50 \%$ (Fig. 2 b-f). In addition, the PtoDET2-OE-L1 line showed a faster growth than that of the L5 line, consistent with PtoDET2 expression levels and BRs contents in these lines. Inversely, transgenic PtoDET2-KO lines displayed retarded growth and lower dry biomass compared with that of WT plants 


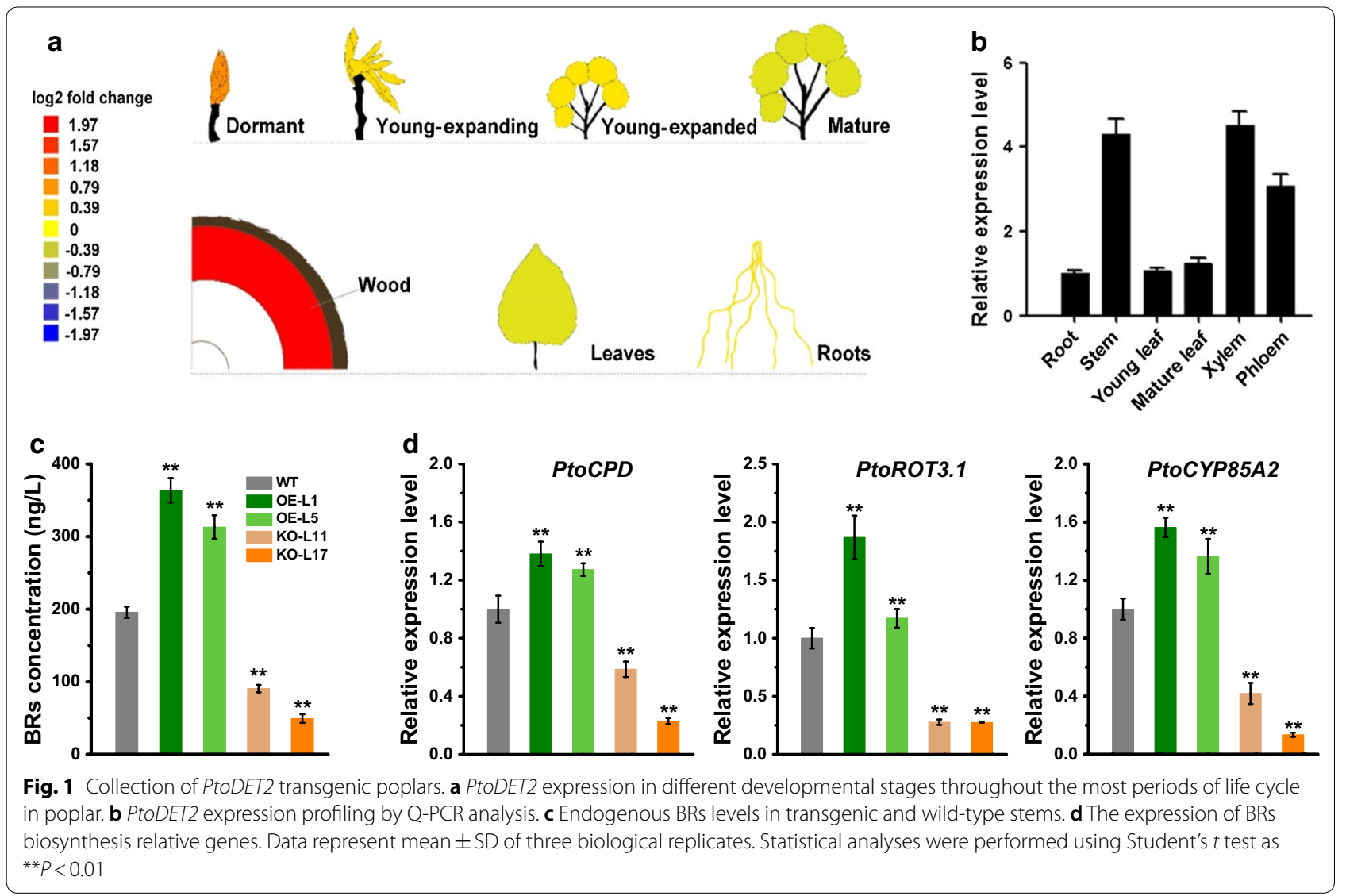

(Fig. 2). Hence, our results indicated that PtoDET2 could significantly increase BRs level for much enhanced plant growth and biomass yield, consistent with the previous findings that BRs-related genes could promote plant growth [31-40].

\section{PtoDET2 affected wood formation and wall polysaccharides biosynthesis}

With respect to the changed biomass yield in the PtoDET2 transgenic plants as described above, this study observed stem morphology and determined cell wall composition in the transgenic plants and WT (Fig. 3). Compared to the WT, the PtoDET2-OE transgenic lines exhibited much expanded xylem area with significantly increased stem diameter and amounts of xylem cell layers as well as larger vessel/fiber cells (Fig. 3a, b), in agreement with the previous reports that BRs promote differentiation of xylem cells [33-35]. Accordingly, we detected significantly increased transcription levels of four representative genes involved in xylem cell differentiation and expansion (Additional file 1: Fig. S3A-D), in supporting for the enhancement of xylem formation and cell size (Fig. 3a, b) in PtoDET2-OE plants.
As plant cell walls represent major components of biomass, we measured cell wall composition of the transgenic plants. By comparison, the two PtoDET2OE transgenic lines contained significantly more cellulose and hemicelluloses levels than those of the WT at $P<0.01$ levels (Fig. 3c-f), but with a similar lignin content (Additional file 1: Table S3). Using Calcofluor white staining for mixed-linkage glucans and monoclonal antibody (LM10) specific for xylan, we observed relatively stronger fluorescent signals in xylem tissues of the PtoDET2-OE lines (Fig. 3c, d), and detected drastically upregulated genes involved in cellulose and hemicelluloses biosynthesis (Additional file 1: Fig. S3C, D), correspondingly for increased celluloses and hemicelluloses levels in the PtoDET2-OE lines. Furthermore, we observed thickened cell walls in xylem tissues of PtoDET2-OE transgenic lines (Fig. 3e), and measured significantly increased cell wall width by $27-36 \%$ relative to WT plants (Fig. 3f). Therefore, these data demonstrated that the PtoDET2OE plants were of significantly increased biomass due to higher cellulose and hemicelluloses levels, and thicker cell wall relative to WT plants. In contrast, reduced xylem development, cell wall disposition and wall thickness were also observed in PtoDET2-KO plants (Fig. 3). 

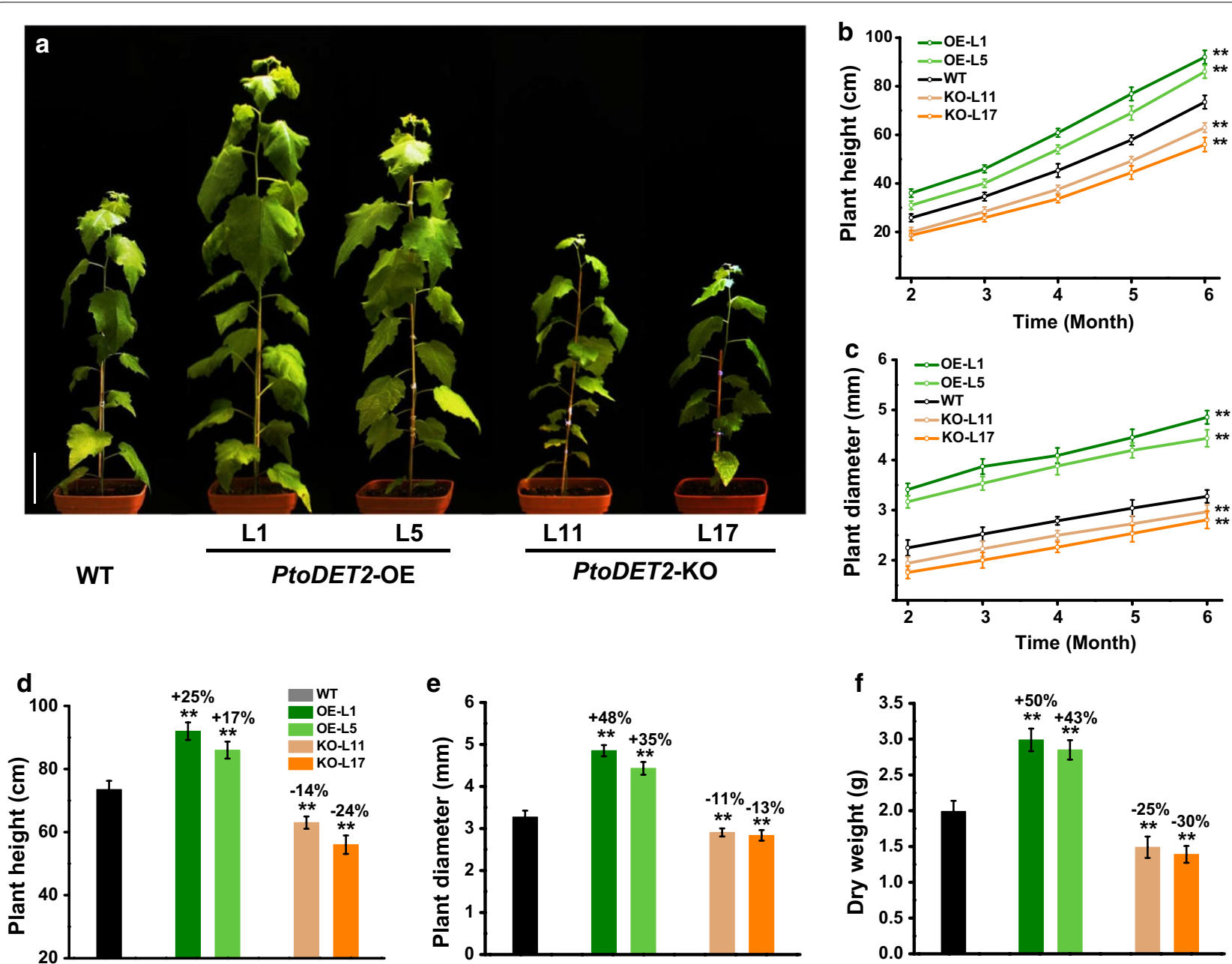

Fig. 2 Measurement of plant growth and biomass yield in transgenic poplar plant. a Images of 5-month-old transgenic poplar lines and wild type (WT); Scale bar as $10 \mathrm{~cm}$. b, c Observation of plant growth in the transgenic lines and WT during time course of 6 months. $\mathbf{d}$-f Plant height, stem diameter and dry weight (biomass yield) in the transgenic lines and WT of 6-month-old. Data represent mean \pm SD of five biological replicates. Student's $t$ test was performed between the transgenic lines and WT as ${ }^{* *} P<0.01$

\section{PtoDET2 enhanced biomass saccharification in transgenic} poplar after chemical pretreatments

Based on the chemical pretreatments with grassy biomass established in our previous works [15-17], here we performed various acid and alkali pretreatments with poplar biomass residues (WT) using a series of concentrations of $\mathrm{H}_{2} \mathrm{SO}_{4}, \mathrm{NaOH}, \mathrm{CaO}$ and green liquor $\left(\mathrm{Na}_{2} \mathrm{~S}+\mathrm{Na}_{2} \mathrm{CO}_{3}\right)$ under different incubation temperatures, and then determined biomass saccharification by calculating hexose yields (\% biomass) released from enzymatic hydrolysis of pretreated biomass residues (Additional file 1: Fig. S4). Hence, four optimal acid and alkali pretreatments $\left(\mathrm{H}_{2} \mathrm{SO}_{4} / 120{ }^{\circ} \mathrm{C} / 20 \mathrm{~min} ; 4 \% \mathrm{NaOH} / 50{ }^{\circ} \mathrm{C} / 2 \mathrm{~h} ; 10 \%\right.$ $\mathrm{CaO} / 50{ }^{\circ} \mathrm{C} / 2 \mathrm{~h}$; and $\mathrm{Na}_{2} \mathrm{~S}+\mathrm{Na}_{2} \mathrm{CO}_{3} / 150{ }^{\circ} \mathrm{C} / 20 \mathrm{~min}$;) were established subjective to the relatively high hexose yields achieved in poplar. Using the four optimal pretreatments, this study compared biomass saccharification between transgenic poplar lines and WT. In general, two PtoDET2-OE lines remained significantly increased biomass saccharification including hexoses and total sugar yields (Fig. 4). By comparison, PtoDET2-KO transgenic lines had reduced total sugar and hexoses yields. In particular, the green liquor $\left(\mathrm{Na}_{2} \mathrm{~S}+\mathrm{Na}_{2} \mathrm{CO}_{3}\right)$ pretreatment caused the most increased total sugar and hexoses yields by $12-20 \%$ and $8-19 \%$ in the PtoDET2-OE lines relative to WT. Furthermore, the $\mathrm{Na}_{2} \mathrm{~S}+\mathrm{Na}_{2} \mathrm{CO}_{3}$ pretreatment led to the highest hexoses and total sugar yields in both transgenic lines and WT, among the four optimal chemical pretreatments, indicating that the $\mathrm{Na}_{2} \mathrm{~S}+\mathrm{Na}_{2} \mathrm{CO}_{3}$ 
(See figure on next page.)

Fig. 3 Observations of plant cell walls in transgenic poplar plant. a Toluidine blue staining of the 6th internode stems of 5-month-old transgenic line and WT (Ph: phloem, C: cambium, Xy: xylem, Xf: xylem fiber cells, P: pith, Ep: epidermis. Scale bars as 50 um). $\mathbf{b}$ Numbers of xylem cell layers and lumen area of individual xylem vessel cell and fiber cell. c Calcofluor staining specific for glucans (scale bars as $100 \mu \mathrm{m}$ ). $\mathbf{d}$ Immunohistochemical fluorescence (green) specific for xylan using LM10 antibody (scale bars as $100 \mu \mathrm{m}$ ). e Scanning electron microscopy (SEM) images (XV: xylem vessel, scale bars as $5 \mu \mathrm{m})$. $\mathbf{f}$ Cell wall composition and cell wall thickness of SEM observation. All data as mean \pm SD. Student's $t$ test was performed between the transgenic line and WT as ${ }^{* *} P<0.01$ ( $n=3$ for cell wall composition, $n=30$ for cell wall thickness, technical replicates)

pretreatment should be most effective for enhancing biomass enzymatic saccharification in poplar.

\section{Improved bioethanol yield and sugar-ethanol conversion rates in PtoDET2-OE lines}

To investigate bioethanol yield and sugar-ethanol conversion rates of transgenic plants, we further performed a classic yeast fermentation using total hexoses released from enzymatic hydrolysis of the pretreated poplar biomass residues. Under four optimal chemical pretreatments, two PtoDET2-OE lines showed significantly higher bioethanol yields (\% biomass) than those of the WT at $P<0.01$ level. In detail, the pretreatment with $\mathrm{H}_{2} \mathrm{SO}_{4}$ or $\mathrm{NaOH}$ could lead to bioethanol yields $19-26 \%$ or $11-17 \%$ increased from PtoDET2-OE lines than WT, whereas $\mathrm{CaO}$ and $\mathrm{Na}_{2} \mathrm{~S}+\mathrm{Na}_{2} \mathrm{CO}_{3}$ pretreatments released about $31-35 \%$ or $22-33 \%$ more bioethanol, compared with WT (Fig. 5a). Since the biomass production was improved in PtoDET2-OE plants, we also accessed the bioethanol yield per plant (mg). Consequently, the PtoDET2-OE plants had increased bioethanol yields by $71-90 \%, 59-75 \%, 87-102 \%$, and $74-100 \%$, after $\mathrm{H}_{2} \mathrm{SO}_{4}, \mathrm{NaOH}, \mathrm{CaO}$ and $\mathrm{Na}_{2} \mathrm{~S}+\mathrm{Na}_{2} \mathrm{CO}_{3}$ pretreatments, respectively (Fig. 5b). Hence, these results suggested that the PtoDET2-OE plants were of consistently enhanced bioethanol production.

During the pretreatment process, a range of sugar and lignin degradation products are produced, such as weak acids, furan derivatives, and phenolic compounds, which have been widely reported as inhibitors of ethanol fermentation. The sugar-ethanol conversion rates were used to assess the critical levels for inhibition of ethanol production by yeast. Compared with WT, the PtoDET2-OE lines revealed significantly improved sugar-ethanol conversion rates under multiple pretreatments (Fig. 5c), while transgenic PtoDET2$\mathrm{KO}$ lines showed reduced ethanol yields and conversion rates (Fig. 5). The results confirmed that PtoDET2-OE lines should release less amounts of toxic byproducts that inhibit yeast fermentation, probably due to its altered cell wall composition and wall polymer features.

\section{Altered lignocellulose features in transgenic poplar plants} It has been demonstrated that lignocellulose features significantly affect biomass enzymatic saccharification under various physical and chemical pretreatments [21-29]. Due to markedly increased cellulose levels in PtoDET2-OE lines, we examined cellulose crystalline index (CrI) and degree of polymerization (DP), which have been examined as major cellulose features negatively affecting biomass enzymatic saccharification. Compared to WT, the PtoDET2-OE lines showed significantly reduced $\mathrm{CrI}$ and DP values by $14-19 \%$ and $10-12 \%$, respectively (Fig. 6a, b). Previous studies show that GH9 genes encoded glycoside hydrolase enzymes play important roles in reducing cellulose CrI and DP [18, 19, 4143]. We found that transcript levels of two representative PtoGH9s were significantly increased in the PtoDET2-OE lines relative to WT (Additional file 1: Fig. S5), supporting the findings of reduced cellulose CrI and DP. As cellobiohydrolase $(\mathrm{CBH})$ enzyme is specific for attacking the reducing ends of $\beta$-1, 4-glucan chains [19], we also performed an enzymatic hydrolysis in vitro using commercial CBHI enzyme (E.C. 3.2.1.91). During the time course of enzymatic hydrolysis, the PtoDET2-OE lines remained to release much more glucose than that of the WT (Fig. 6c), consistent with the previous reports that the reduced cellulose DP could lead to much increased glucose release from CBHI hydrolysis [19].

Meanwhile, we also determined monosaccharide composition of hemicellulose in transgenic plants and WT (Additional file 1: Table S4). By comparison, two PtoDET2-OE lines showed significantly increased arabinose, with reduced xylose/arabinose (Xyl/Ara) ratios than those of the WT (Fig. 6d). The Xyl/Ara ratio of hemicelluloses has been known as the negative factor on biomass enzymatic saccharification in the grassy biomass residues examined [12, 17, 19, 31]. Therefore, we speculate that the significant reduction in the Xyl/Ara ratio might be an additive reason for enhanced biomass saccharification in PtoDET2-OE poplar plants, though the hemicelluloses of grasses and dicots are quite different. In contrast, PtoDET2-KO transgenic lines showed increased CrI, DP, CBHI activity and Xyl/Ara ratio. In addition, this study detected a similar monolignol constituent of lignin between transgenic lines and WT (Additional file 1: Table S4), suggesting that lignin biosynthesis is not altered in all PtoDET2 transgenic poplar plants. 


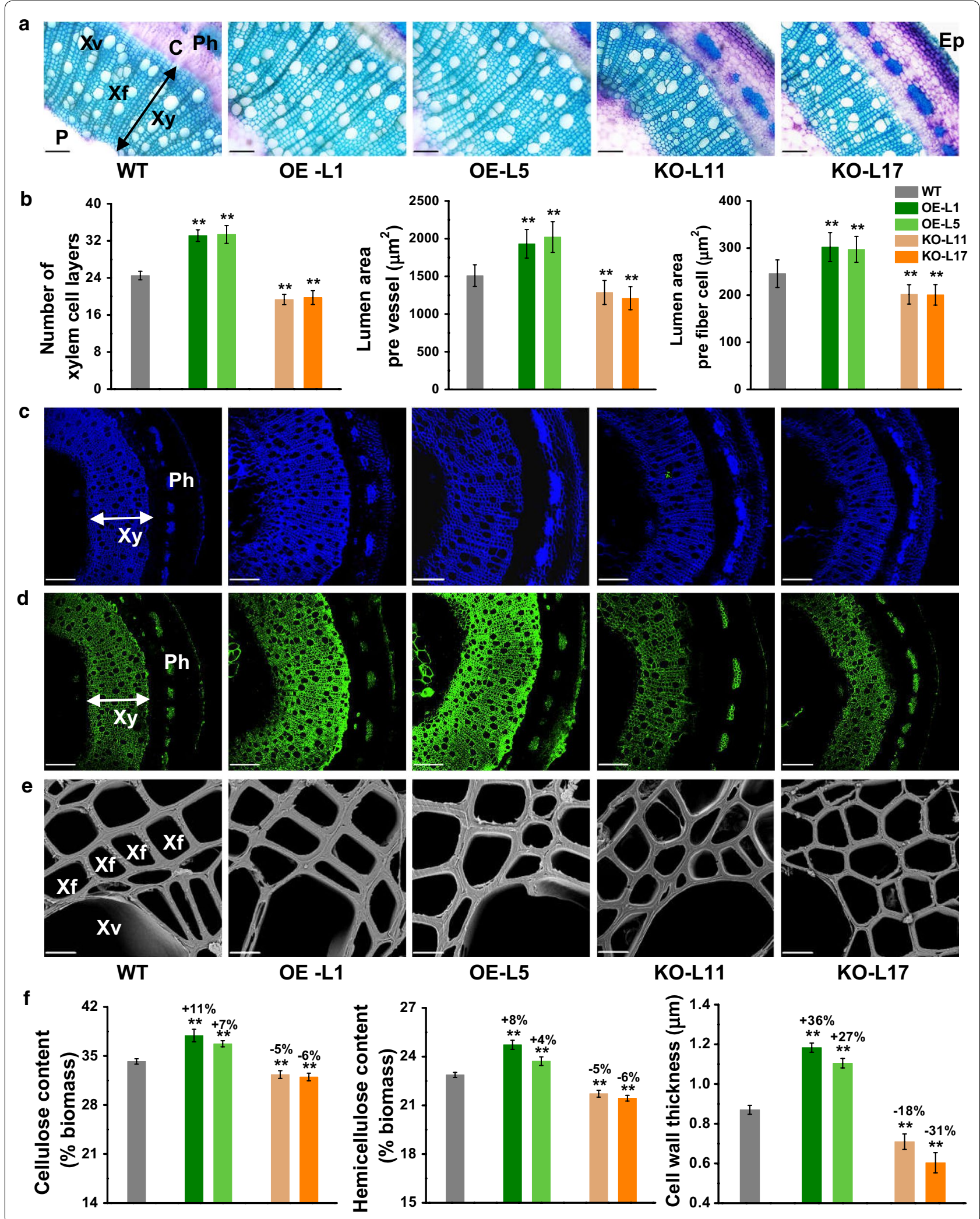



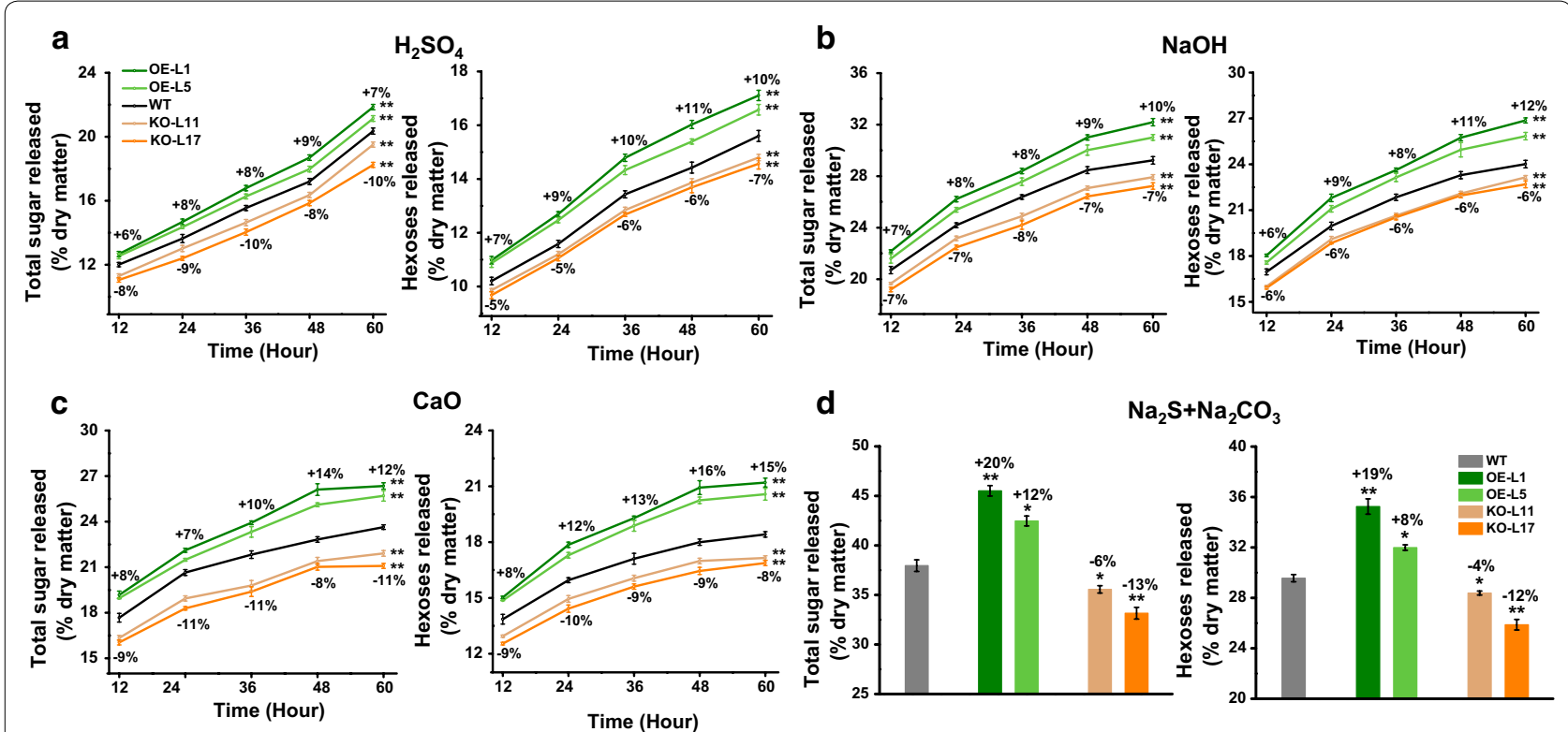

Fig. 4 Analyses of biomass enzymatic saccharification in the transgenic lines and WT. a Total sugar yields and hexose yields released from enzymatic hydrolysis after the pretreatment with $4 \% \mathrm{H}_{2} \mathrm{SO}_{4}, \mathbf{b} 4 \% \mathrm{NaOH}, \mathbf{c} 10 \% \mathrm{CaO}$ or $\mathbf{d} \mathrm{Na}_{2} \mathrm{~S}+\mathrm{Na}_{2} \mathrm{CO}_{3}$ pretreatments. Data represent mean $\pm \mathrm{SD}$ of three technical replicates. All data as mean \pm SD. Student's $t$ test between transgenic line and WT as ${ }^{* *} P<0.01$

\section{Increased lignocellulose porosity and accessibility in PtoDET2-OE lines}

Although lignocellulose features could largely affect biomass enzymatic saccharification for bioethanol production as described above, it has been recently shown that biomass porosity and cellulose accessibility of the pretreated residues are the finalized determinant of biomass enzymatic hydrolysis for bioethanol production $[15,17,18,42-45]$. Given that the $\mathrm{Na}_{2} \mathrm{~S}+\mathrm{Na}_{2} \mathrm{CO}_{3}$ pretreatment is superior to other pretreatments for higher sugar and bioethanol yields in this study, the residues of $\mathrm{Na}_{2} \mathrm{~S}+\mathrm{Na}_{2} \mathrm{CO}_{3}$ pretreatment were used for subsequent enzyme accessibility measurement. We further observed the pretreated biomass residues by scanning electron microscopy (SEM). Compared to the raw materials, the biomass residues obtained from $\mathrm{Na}_{2} \mathrm{~S}+\mathrm{Na}_{2} \mathrm{CO}_{3}$ pretreatment exhibited rougher surface in both PtoDET2 transgenic poplar and WT (Fig. 7a), consistent with the previous reports of the rough biomass residues effective for cellulase enzyme loading and digestion [15, 17, 18, 42-45]. Using the Congored staining approach established recently [43], we measured cellulose accessibility, which was the direct parameter of cellulase enzyme attack on cellulose surface. Despite the similar Congo-red staining areas in raw materials of both transgenic lines and WT, the pretreated residues of PtoDET2-OE lines showed significantly $(P<0.01)$ increased cellulose accessibility than that of WT, with the increased rate of $12-16 \%$, while the decreased rate of $5-6 \%$ in the PtoDET2-KO lines (Fig. 7b), indicating that the $\mathrm{Na}_{2} \mathrm{~S}+\mathrm{Na}_{2} \mathrm{CO}_{3}$ pretreatment was more effective in enhancing cellulose accessibility in the PtoDET2-OE plants.

Since biomass porosity has been defined to account for cellulase enzyme loading and access to cellulose microfibrils [15, 17, 18, 42-45], we also detected biomass porosity of the pretreated residues including surface area and average pore diameter. By comparison, the biomass porosity of PtoDET2-OE lines remained significantly raised than that of the WT at $P<0.01$ level, whereas the PtoDET2-KO lines showed markedly reduced biomass porosity (Fig. 7c, d). The results indicated that increased biomass porosity might result in enhanced biomass enzymatic saccharification in the PtoDET2-OE poplar plants.

\section{Discussion}

Extensive evidences have shown that plant hormones are indispensable in plant growth and development. Recently, BRs were shown to take part in regulating wood formation, xylem differentiation, and cell wall biosynthesis [33-36]. Previous studies have demonstrated that DET2 catalyzes a $5 \alpha$-reduction of multiple related sterols, and DET2 is an important rate-limiting enzyme in the BR biosynthesis pathway [46, 47]. In this study, overexpression of PtoDET2 promoted plant growth and biomass yield, while knockout of PtoDET2 led to a reduced growth (Fig. 2). These phenotypic alterations are consistent 


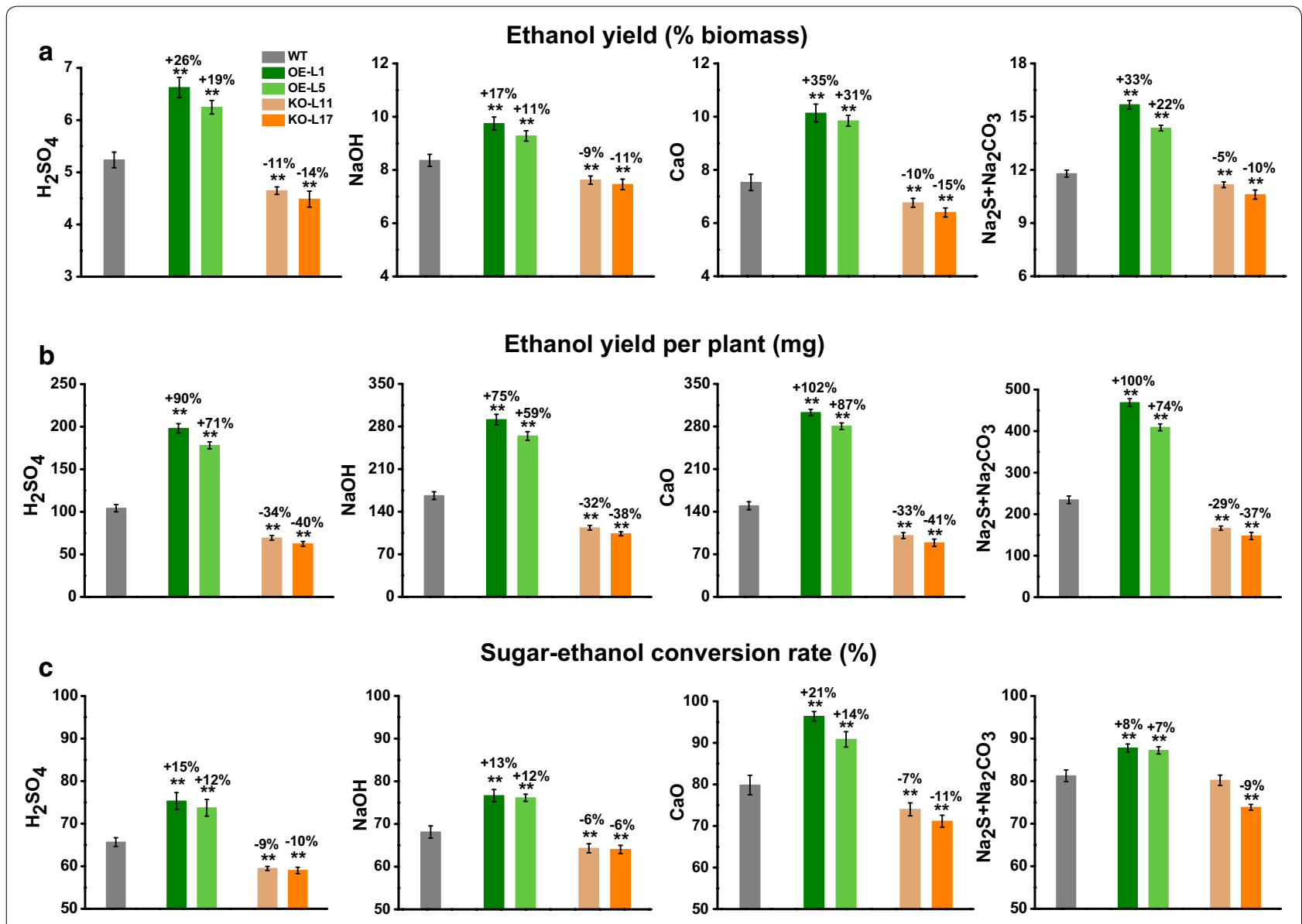

Fig. 5 Detection of bioethanol yield and sugar-ethanol conversion rate in the transgenic lines and WT. a Bioethanol yields (\% biomass) or $\mathbf{b}$ bioethanol yields (per plant) obtained from yeast fermentation using total hexose contents released from enzymatic hydrolysis after pretreatments. c Sugar-ethanol conversion rates under pretreatments. Data represent mean \pm SD of three technical replicates Student's $t$ test was performed between the transgenic line and WT as ${ }^{* *} P<0.01$

with previous studies overexpressing PtoDWF4 and PtCYP85A3 in poplar, which displayed increased stem height and diameter [33, 35]. All these similar phenotypes are probably due to the altered activity of the BR biosynthesis enzyme, thus influencing the levels for endogenous BRs. Hence, in this study BRs might act as a positive regulator in regulating cell number, cell size, cell wall thickness, and cell wall polymers composition in xylem (Fig. 2), finally leading to relatively higher biomass yields in PtoDET2-OE and correspondingly less biomass yields in PtoDET2-KO plants (Fig. 2). In terms of much altered cellulose and hemicelluloses levels in transgenic lines, this study also examined the major lignocellulose features, such as cellulose crystalline index (CrI), degree of polymerization (DP), and hemicellulose compositions. Compared to WT, the PtoDET2-OE lines showed significantly reduced CrI and DP values (Fig. 6a, b), as well as reduced Xyl/Ara ratios (Fig. 6d). Inversely, PtoDET2KO lines showed increased CrI, DP, and Xyl/Ara ratios
(Fig. 6). Taken together, these data implied that PtoDET2 is positively regulates xylem development, cell wall biosynthesis and modification in poplar. It is reported that BRs promote cellulose biosynthesis and biomass accumulation in Arabidopsis, and BR-activated transcription factor BES1 can associate with upstream elements of most cellulose synthase genes (CESA) [48]. In this study, the expression of genes involved in cell differentiation (LBD38, CLE14), cell expansion (EXP5, EXP12), cell wall biosynthesis (CESA, GT) and glycoside hydrolase enzymes genes (GH9) were altered (Additional file 1: Fig. S3). It would be worthwhile to investigate whether the BES1 can bind to the promoter regions of those genes in poplar.

Besides the cellulose and hemicellulose mentioned above, lignin also has effects on biomass enzymatic hydrolysis. In plant cell wall, lignin is a phenolic polymer composed mainly of $p$-coumaryl alcohol, coniferyl alcohol and sinapyl alcohol, and the three monomers are 

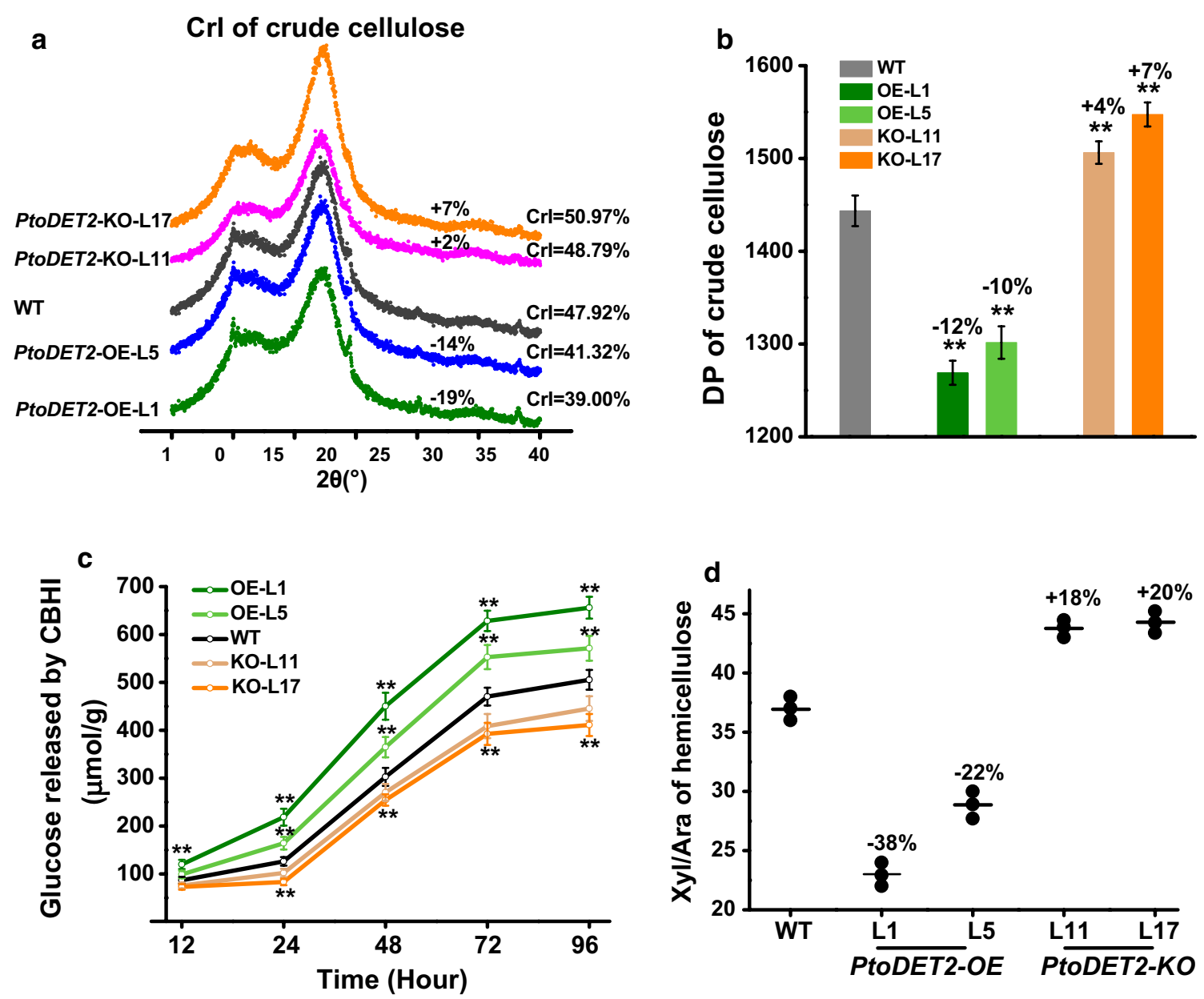

Fig. 6 Comparison of lignocellulose features between the transgenic lines and WT. a Crystalline index (Crl) of crude cellulose. b Degree of polymerization (DP) of crude cellulose. c Glucose yield of the cellobiose released from time-course CBHI hydrolyzes using crude cellulose as substrate. $\mathbf{d}$ Xyl/Ara rate of total hemicelluloses. All data as mean \pm SD of three technical replicates; increased percentage (\%) obtained by subtracting transgenic line value with WT divided by WT. Student's $t$ test was performed between the transgenic line and WT as ${ }^{* *} P<0.01$

cross-linked by ether-, ester- and $\mathrm{C}-\mathrm{C}$ bonds to form a stable and water-proofing lignin complex $[49,50]$. Typically, lignin has a negative impact on biomass digestibility: preventing cellulose microfibril swelling to reduce surface area access of cellulase enzymes, and limiting cellulase action on the cellulose surface $[8,13,14]$. In this study, the $\mathrm{Na}_{2} \mathrm{~S}+\mathrm{Na}_{2} \mathrm{CO}_{3}$ pretreatment led to the highest biomass saccharification and bioethanol yields among the four pretreatments (Figs. 4 and 5). To understand the biomass process for biofuel production under $\mathrm{Na}_{2} \mathrm{~S}+\mathrm{Na}_{2} \mathrm{CO}_{3}$ pretreatment, an analysis of mass balance was performed (Additional file 1: Fig. S6). Although the PtoDET2-OE lines had significantly higher levels of both cellulose and hemicelluloses than WT (Fig. 3f), small amounts of hexoses and pentoses were extracted in both transgenic lines and WT through the $\mathrm{Na}_{2} \mathrm{~S}+\mathrm{Na}_{2} \mathrm{CO}_{3}$ pretreatment (Additional file 1: Fig. S6), suggesting that the $\mathrm{Na}_{2} \mathrm{~S}+\mathrm{Na}_{2} \mathrm{CO}_{3}$ pretreatment is effective to restore cellulose and hemicellulose for sequential enzymatic hydrolysis and final bioethanol production. Under $\mathrm{Na}_{2} \mathrm{~S}+\mathrm{Na}_{2} \mathrm{CO}_{3}$ pretreatment, lignin was predominant in the extraction of both transgenic poplar lines and WT. We further observed potential alteration of wall polymer linkage resulting from the $\mathrm{Na}_{2} \mathrm{~S}+\mathrm{Na}_{2} \mathrm{CO}_{3}$ pretreatment using Fourier transform infrared (FTIR) spectroscopy (Additional file 1: Table S5 and Fig. S7). Compared to raw materials, the $\mathrm{Na}_{2} \mathrm{~S}+\mathrm{Na}_{2} \mathrm{CO}_{3}$ pretreated biomass residues showed apparent variations of four major peaks $\left(1244,1508,1615,1736 \mathrm{~cm}^{-1}\right)$, which were characteristic for lignin interaction with wall networks in both transgenic lines and WT (Additional file 1: Table S5 and Fig. S7). For instance, the absorption bands located at $1736 \mathrm{~cm}^{-1}(\mathrm{C}=\mathrm{O})$ and $1244 \mathrm{~cm}^{-1}(\mathrm{C}-\mathrm{O}-\mathrm{C})$ could not be 


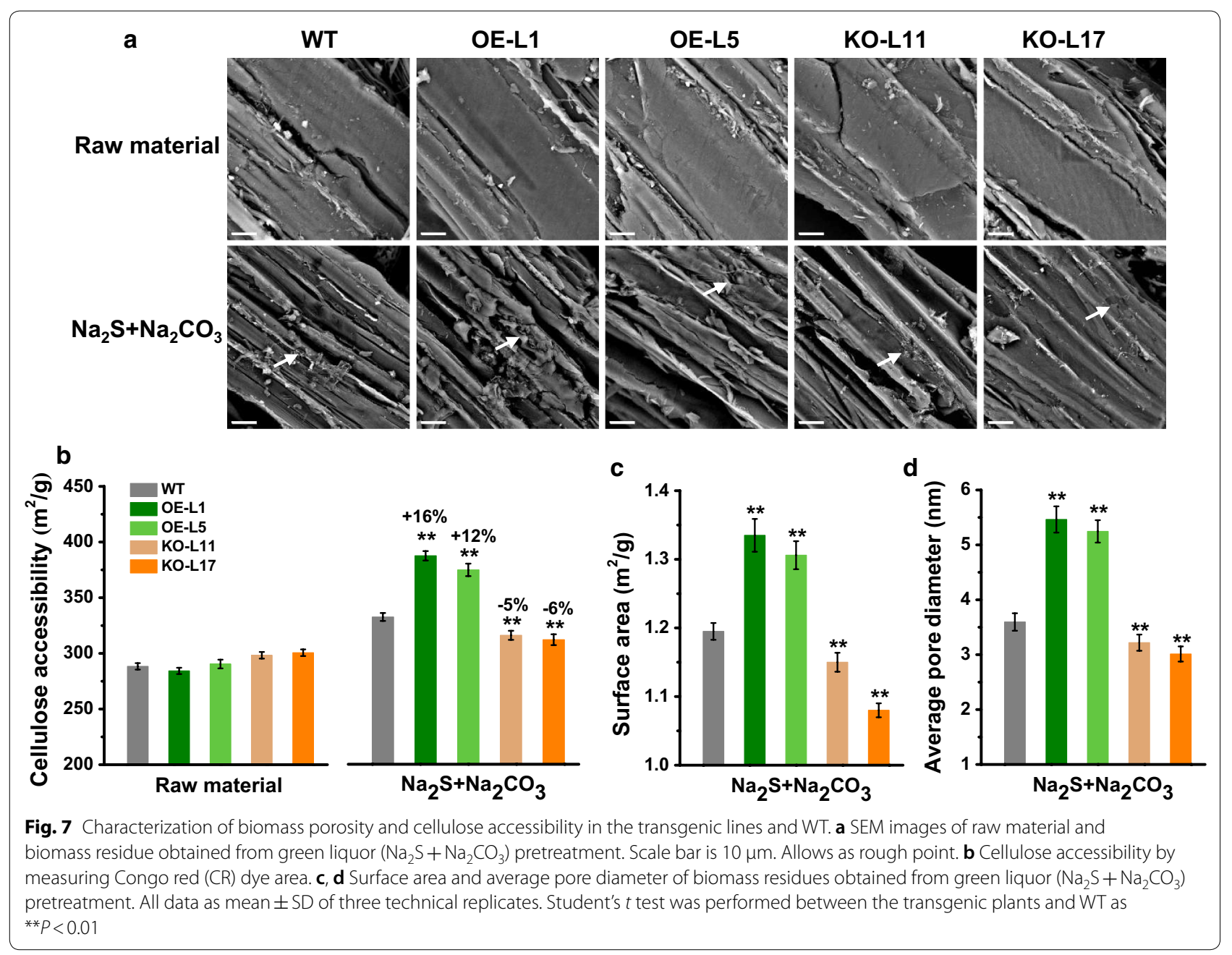

found in the pretreated residues, which were referred as either ester-linked acetyl and uronic groups of hemicelluloses or the carboxylic acid groups of ferulic and $p$-coumaric acids of lignin and hemicelluloses [51]. The FTIR profiling confirmed that the $\mathrm{Na}_{2} \mathrm{~S}+\mathrm{Na}_{2} \mathrm{CO}_{3}$ pretreatment was also effective for lignin extraction in woody plants, consistent with the previous reports in grasses $[13,25,27]$. Despite the transgenic lines and WT had a similar lignin content in the raw materials (Additional file 1: Table S3), after $\mathrm{Na}_{2} \mathrm{~S}+\mathrm{Na}_{2} \mathrm{CO}_{3}$ pretreatment, $70.1 \mathrm{~g}$ lignin was extracted in the PtoDET2-OE line, but only $43.7 \mathrm{~g}$ and $42.3 \mathrm{~g}$ lignin were extracted in the WT and PtoDET2-KO line, respectively (Additional file 1: Fig. S6), indicating that the $\mathrm{Na}_{2} \mathrm{~S}+\mathrm{Na}_{2} \mathrm{CO}_{3}$ pretreatment is more effective for lignin extraction in the PtoDET2-OE line, probably due to its altered lignocellulose features and the weaker cross link between lignin and other wall polysaccharides. The more effective for lignin extraction in PtoDET2-OE lines is likely to reduce the non-specific binding of cellulases to lignin, leading to more cellulase enzymes action on the cellulose surface.

Furthermore, this study detected enzyme accessibility of raw materials and pretreated residues. As a result, the biomass residues obtained from $\mathrm{Na}_{2} \mathrm{~S}+\mathrm{Na}_{2} \mathrm{CO}_{3}$ pretreatment exhibited much rougher surface and increased enzyme accessibility in both transgenic poplar and WT, compared to the raw materials. This indicates that a high proportion of lignin was extracted from $\mathrm{Na}_{2} \mathrm{~S}+\mathrm{Na}_{2} \mathrm{CO}_{3}$ pretreatment, which largely increased biomass porosity and cellulose accessibility for cellulases access and loading, leading to remarkably enhanced biomass enzymatic saccharification and higher ethanol yield. In terms of sugar-ethanol conversion rates, the $\mathrm{Na}_{2} \mathrm{~S}+\mathrm{Na}_{2} \mathrm{CO}_{3}$ pretreatment caused much higher sugar-ethanol conversion rates than those of the other two optimal chemical $\left(\mathrm{H}_{2} \mathrm{SO}_{4}, \mathrm{NaOH}\right)$ pretreatments (Fig. 5c), confirming that this pretreatment should release less byproducts that inhibit yeast fermentation. Thereby, $\mathrm{Na}_{2} \mathrm{~S}+\mathrm{Na}_{2} \mathrm{CO}_{3}$ pretreatment is a relatively high effective pretreatment with 
lower amounts of toxic byproducts that inhibit yeast fermentation and less corrosive compounds that damage the pretreatment equipment or cause environmental pollution.

In addition, this study compared bioethanol yields (\% biomass) based on the previously reported ones in three major woody plants from different biomass pretreatments (Additional file 1: Table S6). Under the $\mathrm{Na}_{2} \mathrm{~S}+\mathrm{Na}_{2} \mathrm{CO}_{3}$ pretreatment, the best transgenic poplar line (PtoDET2OE-L1) exhibited the highest bioethanol yield of $15.68 \%$ among all reported bioethanol ones in three woody plants even though under relatively stronger pretreatment conditions [52-56]. Importantly, the bioethanol yield of our transgenic poplar (L1) line was also higher than that of the previous transgenic poplar line (GAUT4-KD and MOMT4-OE) as recently reported [52, 53]. However, both wild types (poplar) of this work and the previous study showed a similar bioethanol yield [53], suggesting that DET2 is an effective gene target for production of high-yielding biomass with improved properties for lignocellulosic biofuel production, and the $\mathrm{Na}_{2} \mathrm{~S}+\mathrm{Na}_{2} \mathrm{CO}_{3}$ pretreatment is a relatively highly effective pretreatment.

Based on all findings obtained in this study, we proposed a mechanistic model (Additional file 1: Fig. S8) to explain why the BRs-overproduced transgenic poplar plants have much increased biomass saccharification for the higher bioethanol production after $\mathrm{Na}_{2} \mathrm{~S}+\mathrm{Na}_{2} \mathrm{CO}_{3}$ pretreatment as shown below. (1) BRs regulated the expression of genes involved in cell differentiation, cell expansion, and cell wall biosynthesis (Additional file 1: Fig. S3), which results in increased xylem cell number, cell size, cell wall thickness, and cell wall polymers composition (Fig. 3), finally leading to relatively $50 \%$ higher biomass yields in PtoDET2OE (Fig. 2). The cellulose and hemicelluloses, rather than lignin, were much more deposited in the thickened cell walls of PtoDET2-OE lines, leading to significantly high hexose/glucose yield for ethanol fermentation (Figs. 3, 4, 5). (2) Recent findings indicate that lignocellulose CrI, DP, and hemicellulosic Xyl/Ara were mainly negative factors for biomass enzymatic saccharification. In this study, the PtoDET2-OE lines had reduced cellulose CrI and DP, and hemicellulosic Xyl/Ara (Fig. 6), which led to an integrated positive impact on biomass enzymatic saccharification. (3) The optimal $\mathrm{Na}_{2} \mathrm{~S}+\mathrm{Na}_{2} \mathrm{CO}_{3}$ pretreatment is more effective for lignin extraction (Additional file 1: Figs. S6 and S7), which reduced the non-specific binding of cellulases to lignin, leading to more cellulase enzymes action on the cellulose surface. (4) The reduced cellulose CrI, DP, hemicellulosic $\mathrm{Xyl} / \mathrm{Ara}$, and the relatively high proportion of lignin extraction largely increased biomass porosity and cellulose accessibility for cellulases access and loading (Fig. 7, Additional file 1: Fig. S8), leading to remarkably enhanced biomass enzymatic saccharification and high sugar-ethanol conversion allowed to maximize bioethanol yield in the PtoDET2-OE plants.

\section{Conclusion}

The present study generated BRs levels improved transgenic poplar by overexpression of the PtoDET2, a brassinosteroids biosynthesis gene. The BRs-improved plants exhibited increased xylem development and cell wall polymer deposition, resulting in largely enhanced biomass yield. Importantly, the PtoDET2-OE poplar showed significantly improved lignocellulose features such as reduced cellulose CrI, DP, hemicellulose Xyl/Ara ratio, and increased biomass porosity and accessibility, leading to remarkably enhanced biomass enzymatic saccharification and bioethanol yield. Moreover, this study compared four chemical pretreatments, and took the $\mathrm{Na}_{2} \mathrm{~S}+\mathrm{Na}_{2} \mathrm{CO}_{3}$ as an optimal one for efficient enzymatic hydrolysis with less secondary pollution release. Hence, this study provides a potent strategy for high cellulosic ethanol production by regulating brassinosteroids biosynthesis, and green-like biomass process for woody plants and beyond.

\section{Materials and methods \\ Experimental procedures \\ Collection of transgenic plants}

The sequences of DET2 were obtained from JGI (https ://phytozome.jgi.doe.gov/pz/portal.html), and aligned using ClustalW program implemented in MEGA7 with 1000 bootstrap replicates. The phylogenetic tree was constructed by MEGA7 with neighbor-joining (NJ) method. The GenBank accession numbers for genes used in this study are listed in Additional file 1: Table S1.

The full-length PtoDET2 cDNA was cloned from Populus tomentosa, verified by sequencing, and inserted into the plant binary vector pCXSN under the control of $35 \mathrm{~S}$ promoter. Three CRISPR/Cas9 target sites of PtoDET2 were assembled into binary pYLCRIPSR/Cas 9 vector based on their $\mathrm{GC}$ abundance screened in the online tool ZiFiT TARGETER v.4.2 (http://zifit.partn ers.org/ZiFiT/Introduction.aspx) [57]. The constructs were introduced into Agrobacterium tumefaciens strain EHA105 and transferred into P. tomentosa by Agrobacterium-mediated transformation as described previously [58]. The transgenic lines were selected based on the hygromycin selection and PCR analysis. To identify CRISPR/Cas9-mediated mutation of PtoDET2 in transgenic poplar plants, the PtoDET2 genomic fragment was cloned into the pMD19-T vector (Takara) and at least 20 clones for each transgenic line were randomly selected for sequencing. All primers used are listed in Additional file 1: Table S2. 


\section{Plant growth conditions and sample isolation}

P. tomentosa Carr. plants were grown in a greenhouse under conditions of $16 / 8 \mathrm{~h} \mathrm{light/dark}$ cycle with the 4500 lx supplementary light at $22-25{ }^{\circ} \mathrm{C}$ and relative humidity $\sim 60 \%$. Poplar plants were watered according to the evapotranspiration demands during different growth stages and fertilized with $1 / 2$ strength Hoagland nutrient solutions. Measurement of plant growth was carried out on 10 plants for each WT and transgenic line, deleted 2-3 maximum and 2-3 minimum values, finally calculated the average values of the remained 5 plants. For biomass saccharification and cell wall composition analyses, around $\sim 10 \mathrm{~cm}$ of the bottom part of the stems from 5 plants were harvested and the bark were peeled. The peeled stem samples were air-dried, the pith removed, the remaining tissues milled to a particle size of 20 mesh $(0.85 \mathrm{~mm})$, and the ground samples used for analyses.

\section{Measurement of BR content}

The first elongating internodes of 1-month-old soil PtoDET2-OE, and wild-type plants were used to measure the content of BRs. Samples of tissue powder were homogenized in PBS (PH7.2-7.4, 0.1 M). The supernatants were collected and assayed by Plant Brassinolide (BR) ELISA Kit (Beijing Chenglin Biotechnology Company, China).

\section{Chemical pretreatment and biomass enzymatic hydrolysis}

Dried and milled poplar was used for analysis of sugar yield. Chemical pretreatment and sequential enzymatic hydrolysis were performed as described previously with minor modifications [16, 59]. For $\mathrm{H}_{2} \mathrm{SO}_{4}$ pretreatment: the well-mixed biomass samples were treated with $6 \mathrm{~mL}$ $\mathrm{H}_{2} \mathrm{SO}_{4}$ under various concentrations $(0 \%, 1 \%, 2 \%, 4 \%, 8 \%$ $\mathrm{v} / \mathrm{v}$ ) at $120{ }^{\circ} \mathrm{C}$ for $20 \mathrm{~min}$, then shaken under $150 \mathrm{rpm}$ at $50{ }^{\circ} \mathrm{C}$ for $2 \mathrm{~h}$. For $\mathrm{NaOH}$ pretreatment: the well-mixed biomass samples were incubated with $6 \mathrm{~mL} \mathrm{NaOH}$ under various concentrations $(0 \%, 1 \%, 2 \%, 4 \%, 8 \% \mathrm{w} / \mathrm{v})$ shaken at $50{ }^{\circ} \mathrm{C}$ for $2 \mathrm{~h}$. For $\mathrm{CaO}$ pretreatment, the well-mixed biomass samples were treated with $\mathrm{CaO}$ at various concentrations $(0 \%, 2 \%, 5 \%, 10 \%, 20 \% \mathrm{w} / \mathrm{w})$ shaken at $50{ }^{\circ} \mathrm{C}$ for $48 \mathrm{~h}$. For $\mathrm{Na}_{2} \mathrm{~S}+\mathrm{Na}_{2} \mathrm{CO}_{3}$ pretreatment, solution was prepared by mixing $\mathrm{Na}_{2} \mathrm{~S}$ and $\mathrm{Na}_{2} \mathrm{CO}_{3}$ with a sulfidity (percent ratio of $\mathrm{Na}_{2} \mathrm{~S}$ to the sum of $\mathrm{Na}_{2} \mathrm{~S}$ and $\mathrm{Na}_{2} \mathrm{CO}_{3}$ on $\mathrm{Na}_{2} \mathrm{O}$ basis) of $30 \%$. The samples were first impregnated with $\mathrm{Na}_{2} \mathrm{~S}+\mathrm{Na}_{2} \mathrm{CO}_{3}$ solution at $60{ }^{\circ} \mathrm{C}$ for $30 \mathrm{~min}$. Then temperature was raised at the rate of $3{ }^{\circ} \mathrm{C} / \mathrm{min}$ to the target temperature $\left(130-170{ }^{\circ} \mathrm{C}\right)$ and maintained for scheduled time $(20 \mathrm{~min})$. After pretreatments, the pretreated residues were washed with distilled water for 3-5 times until pH 7.0 for following enzymatic hydrolysis.

Enzymatic hydrolysis: the pretreated biomass residues were washed with mixed-cellulase reaction buffer $(0.2 \mathrm{M}$ acetic acid-sodium acetate, $\mathrm{pH} 4.8$ ), then incubated with $6 \mathrm{~mL}(1.6 \mathrm{~g} / \mathrm{L})$ of mixed-cellulases (Imperial Jade Biotechnology Co., Ltd. Ningxia 750002, China) co-supplied with $1 \%$ Tween-80. The sealed samples were shaken under $150 \mathrm{rpm}$ for $60 \mathrm{~h}$ at $50{ }^{\circ} \mathrm{C}$. After centrifugation at $3000 \mathrm{~g}$ for $5 \mathrm{~min}$, the supernatants were collected for pentoses and hexoses assay. All experiments were performed using five representative plants in triplicate.

\section{Yeast fermentation and ethanol measurement}

The yeast fermentation was conducted using Saccharomyces cerevisiae strain (Angel yeast Co., Ltd., Yichang, China) as previously described by Fan et al. [16] with minor modification. The activated yeast (dissolved in $0.2 \mathrm{M}$ phosphate buffer, $\mathrm{pH} 4.8$ ) was inoculated into the mixture of enzymatic hydrolysates and residues with initial cell mass concentration at $0.5 \mathrm{~g} / \mathrm{L}$. The fermentation experiments were performed at $37^{\circ} \mathrm{C}$ for $48 \mathrm{~h}$, and distilled for determination of ethanol content. Ethanol content was measured using the dichromate oxidation method. All experiments were performed using five representative plants in triplicate.

\section{Plant cell wall fractionation and determination}

Plant cell wall fractionation and assay method were conducted as described previously by Peng et al. [60] with minor modification, all experiments were performed in the technical triplicates. After removal of soluble sugars, lipid, starch and pectin from consecutive extractions with phosphate buffer ( $\mathrm{pH}$ 7.0), chloroform-methanol, dimethyl sulphoxide/water, and $0.5 \%(\mathrm{w} / \mathrm{v})$ ammonium oxalate. The crude cell walls were further suspended with the $4 \mathrm{M} \mathrm{KOH}$ containing $\mathrm{NaBH}_{4}(1.0 \mathrm{mg} / \mathrm{mL})$, and washed three times with distilled water, the combined supernatants (KOH and distilled water) were used as $\mathrm{KOH}$ extractable hemicelluloses fraction. The remaining pellets were dissolved in $72 \% \mathrm{H}_{2} \mathrm{SO}_{4}(\mathrm{w} / \mathrm{w})$ for $1 \mathrm{~h}$ at $25^{\circ} \mathrm{C}$, and after centrifugation, the supernatants were collected to determine hexose as cellulose level. Total hemicelluloses were calculated by measuring hexose and pentose of the hemicellulose fraction and the pentose of the remained cellulose pellets.

GC-MS analysis (SHIMADZU GCMS-QP2010 Plus) was performed for monosaccharide composition detection of hemicellulose as previously described by Fan et al. [61]. GC-MS analytical conditions: Restek Rxi-5ms, $30 \mathrm{~m} \times 0.25 \mathrm{~mm}$ ID $\times 0.25 \mathrm{um}$ df column. Carrier gas: He. Injection method: split. Injection port: $250{ }^{\circ} \mathrm{C}$, interface: $250{ }^{\circ} \mathrm{C}$. Injection volume: $1.0 \mu \mathrm{L}$. The temperature program: from $170{ }^{\circ} \mathrm{C}$ (held for $12 \mathrm{~min}$ ) to $220^{\circ} \mathrm{C}$ (held for $8 \mathrm{~min}$ ) at $3{ }^{\circ} \mathrm{C} / \mathrm{min}$. Ion source temperature: $200{ }^{\circ} \mathrm{C}$, ACQ Mode: SIM. The mass spectrometer was operated in the EI mode with ionization energy of $70 \mathrm{eV}$. Mass spectra 
were acquired with full scans based on the temperature program from 50 to $500 \mathrm{~m} / \mathrm{z}$ in $0.45 \mathrm{~s}$.

Total lignin content includes acid-insoluble and -soluble lignin was determined by two-step acid hydrolysis method as described [62]. The crude cell wall samples were hydrolyzed with $67 \% \mathrm{H}_{2} \mathrm{SO}_{4}(\mathrm{v} / \mathrm{v})$ at $25{ }^{\circ} \mathrm{C}$ for 90 min with a gentle shaking at $150 \mathrm{rpm}$, and subsequently diluted to $3.97 \%(\mathrm{w} / \mathrm{w})$ with distilled water and heated at $115{ }^{\circ} \mathrm{C}$ for $60 \mathrm{~min}$. The acid-soluble lignin was solubilized during the hydrolysis process, and was measured by UV spectroscopy at $205 \mathrm{~nm}$. The remaining residues were placed in a muffle furnace at $575 \pm 25^{\circ} \mathrm{C}$ for $4 \mathrm{~h}$ for the acid-insoluble lignin assay. Lyophilized extractive-free material was used for lignin derived monomers analysis. The thioacidolysis method [63] was used to determine lignin composition. $\mathrm{G}$ and $\mathrm{S}$ lignin was isolated and quantified by GC-MS using a Hewlett-Packard 5890 series II gas chromatograph with a 5971 series mass selective detector (column: HP-1, $60 \mathrm{~m} \times 0.25 \mathrm{~mm}$, $0.25 \mu \mathrm{m}$ film thickness). Mass spectra were recorded in electron impact mode $(70 \mathrm{eV})$, and the scanning range was $60-650 \mathrm{mz}^{-1}$.

FTIR spectroscopy was performed to observe the chemical linkages in the raw and pretreated samples using a PerkinElmer spectrophotometer (NEXUS 470, Thermo Fisher Scientific, Waltham, MA, USA), as described by Cheng et al. [50]. The well-dried biomasses were finely powdered to reduce scattering losses and deformations in the absorption band. The samples (2-4 mg) were dispersed in $\mathrm{KBr}$ at a weight ratio of 1:100 and subsequently pressed to produce a transparent pelletized disc by applying $1 \mathrm{MPa}$ pressure for at least $2 \mathrm{~min}$. The pelletized disc samples were positioned in the path of IR light and the spectra were recorded in absorption mode over 32 scans at a resolution of $4 \mathrm{~cm}^{-1}$ in the range of 4000 to $400 \mathrm{~cm}^{-1}$.

\section{Detection of cellulose features (Crl, DP)}

The lignocellulose crystalline index (CrI) was detected with crude cell wall materials as described by Fan et al. [16]. Essentially, crystalline cellulose was extracted using $4 \mathrm{M} \mathrm{KOH}$ (containing $1.0 \mathrm{mg} / \mathrm{mL}$ sodium borohydride) followed by $8 \%(\mathrm{w} / \mathrm{v}) \mathrm{NaClO}_{2}$ with $1.5 \%$ acetic acid at $25{ }^{\circ} \mathrm{C}$ for $72 \mathrm{~h}$. The pellet was washed to neutral and dried before examination with X-ray diffraction (XRD) using Rigaku-D/MAX instrument (Ultima III, Japan). The biomass powder was laid on the glass sample holder $(35 \times 50 \times 5 \mathrm{~mm})$ and detected under plateau conditions. Ni-filtered $\mathrm{Cu} \mathrm{K} \alpha$ radiation $(\lambda=0.154056 \mathrm{~nm})$ generated at voltage of $40 \mathrm{kV}$ and current of $18 \mathrm{~mA}$, and scanned at speed of $0.0197^{\circ} / \mathrm{s}$ from 10 to $45^{\circ}$. The CrI was estimated using the intensity of the 200 peak $\left(I_{200}, \theta=22.5^{\circ}\right)$ and the intensity at the minimum between the 200 and 110 peaks $\left(I_{\text {am }}\right.$, $\left.\theta=18.5^{\circ}\right)$ as the follow: $\mathrm{CrI}=100 \times\left(I_{200}-I_{\mathrm{am}}\right) / I_{200}$. Standard error of the CrI method was detected using five representative samples in triplicate.

The crude cellulose DP assay was performed using viscosity method as previously described according to the equation: $\mathrm{DP}^{0.905}=0.75[\eta][10]$. And $[\eta]$ is the intrinsic viscosity of the solution. All experiments were performed at $25 \pm 0.5 \mathrm{C}$ using an Ubbelohde viscosity meter and cupriethylenediamine hydroxide (Cuen) as the solvent. The intrinsic viscosity was calculated by interpolation using the USP table (USP, 2002) that lists the predetermined values of the product of intrinsic viscosity and concentration. The $[\eta]$ for cellulose samples exhibiting relative viscosity $\left(\eta_{\text {re }}\right)$ values between 1.1 and 9.9. $\eta_{\text {rel }}$, was calculated using the equation: $\eta_{\text {rel }}=t / t_{0}$, where $\mathrm{t}$ and $\mathrm{t}_{0}$ are the efflux times for the cellulose solution and Cuen (blank) solvent, respectively. Standard error of the DP method was detected using five representative samples in triplicate.

\section{Microscopic observation}

The sixth internode of the 5-month-old poplar stems were fixed in FAA buffer (formaldehyde:glacial acetic acid: 50\% ethanol, 1:1:18). After embedding in paraffin, the stems were cross sectioned by using an Ultra-Thin Semiautomatic Microtome (FINESSE 325, Thermo) and stained with $0.05 \%(\mathrm{w} / \mathrm{v})$ toluidine blue $\mathrm{O}$ and then observed under Zeiss optical microscope (Zeiss, Oberkochen, Germany).

For cellulose staining, sections were incubated with Calcofluor white M2R fluorochrome (Sigma; $0.25 \mu \mathrm{g} /$ $\mathrm{mL}$ in $\mathrm{dH}_{2} \mathrm{O}$ ). For hemicelluloses staining, sections were incubated with LM10 (http://glycomics.ccrc.uga.edu/ wall2/antibodies/antibodyHome.html). Sections were imaged using a microscope (Olympus BX-61, Japan) equipped with the following filter sets: $350 / 450 \mathrm{~nm}$ (ex/ em) and 490/520 nm (ex/em) for visualizing Calcofluor white-stained cell walls and green emission of the FITC fluorochrome, respectively.

Scanning electron microscopy (SEM) was used to observe cell wall structures and the effects of pretreatment. Cross sections were obtained by dissecting transversely with razor blade by hand and the samples were attached using double-sided stick tapes. The samples were observed by SEM (PhenomtmPure FEI, USA) following the manual's recommendations and images were captured digitally. For the effects of pretreatment, the biomass residues after pretreatment were dried at $50{ }^{\circ} \mathrm{C}$ to constant weight, and the surfaces of biomass samples were observed using SEM. Each sample was observed 10 times, and a representative image was used in this study. 
Crude cellulose hydrolysis by $\beta$-1,4-exoglucanase (CBHI)

$\mathrm{CBHI}$ enzyme hydrolysis assay was performed using crude cellulose samples as described by Huang et al. [19]. Samples were incubated with CBHI (E.C. 3.2.1.91; Megazyme, USA) at $50{ }^{\circ} \mathrm{C}$ for a time course of reactions. After centrifugation, the supernatants were collected and treated with TFA, and Myo-inositol was added as the internal standard. The supernatants were then dried under vacuum to remove TFA. Distilled water and freshly prepared solution of sodium borohydride were added to each sample, incubated at $40{ }^{\circ} \mathrm{C}$ for $1 \mathrm{~h}$, and the excess sodium borohydride was decomposed by adding acetic acid. 1-methylimidazole and the acetic anhydride were added and mixed well to perform an acetylation reaction. The excess acetic anhydride was decomposed by adding distilled water. Dichloromethane was added, mixed gently, and left standing for phase separation. The collected samples were analyzed using GC-MS (SHIMADZU GCMS-QP2010 Plus) as described above.

\section{Measurement of cellulose accessibility and biomass porosity}

Congo red stain was applied to estimate cellulosic surface area accessible for degrading cellulases as previously described by Wiman et al. [44]. $100 \mathrm{mg}$ sample was treated with Congo red solution under increasing concentrations $(0.25,0.50,0.75,1.0,1.5,2.0 \mathrm{mg} / \mathrm{mL})$ in $0.3 \mathrm{M}$ phosphate buffer (pH 6.0) with $1.4 \mathrm{mM} \mathrm{NaCl}$ at $60^{\circ} \mathrm{C}$ for $24 \mathrm{~h}$ with $200 \mathrm{rpm}$ rotation speed. After centrifugation at $8000 \mathrm{~g}$ for $5 \mathrm{~min}$, the absorbance of the supernatant was recorded at $498 \mathrm{~nm}$. Adsorption of Congo red (Ae, mg/g) was calculated by Langmuir model using the following equation: $\mathrm{Ae}=(\mathrm{Ci}-\mathrm{Ce}) \times V /(M \times 1000) . V$, total volume $(\mathrm{mL})$ at determination; $M$, initial weight of biomass (g). In this study, $V$ was $10 \mathrm{~mL}, M$ was $0.1 \mathrm{~g}$. Ci and Ce, Congo red concentrations $(\mathrm{mg} / \mathrm{L})$ before or after adsorption, calculated using standard curve from Congo red solutions at 20, 40, 60, 80, 100 and $120 \mathrm{mg} / \mathrm{L}$ concentrations.

Measurements of specific surface area, and mean pore radius were conducted using the multipurpose apparatus Micrometrics ASAP 2460 (USA) as described by Brunauer et al. [64], Liu et al. [65], and Li et al. [18]. The specific surface area was calculated by the BrunauerEmmett-Teller (BET) method with the adsorption data at the relative pressure $(P / P O)$ range of $0.05-0.3$. The total pore volumes were measured at $P / P O=0.95$. The average pore diameter was obtained using the iterative method of Barrett-Joyner-Halenda (BJH) and BET.

\section{Statistical analysis}

Biological triplicate samples were collected for 5 plants of each transgenic line selection, and chemical analysis was performed in technical triplicates. The SPSS statistical software was used for data analysis. Statistical analysis was performed by Student's $t$ tests (two tail distribution and two samples with unequal variances) as ${ }^{*} P<0.05$ and ${ }^{* *} P<0.01$.

\section{Supplementary information}

Supplementary information accompanies this paper at https://doi. org/10.1186/s13068-020-1652-z.

Additional file 1: Table S1. Information of DET2 genes. Pe: Populus euphratica, Ptr: P. trichocarpa, Me: Manihot esculenta, Jc: Jatropha curcas, Ai: Arachis ipaensis, Vv: Vitis vinifera, Ha: Helianthus annuus, Pb: Pyrus x bretschneideri, At: A. thaliana, Cq: Chenopodium quinoa, Mn: Morus notabilis, Eg: Eucalyptus grandis, Gr: Gossypium raimondii, Gb: Gossypium barbadense, Gh: Gossypium hirsutum, SI: Solanum lycopersicum, Sc: Solanum chacoense, Os: Oryza sativa, Zm: Zea mays, Sb: Sorghum bicolor. Table S2. Gene primers used for PCR amplification. Table S3. Total pectin and lignin contents (\% biomass) in stems of transgenic lines and WT. All data are given as mean \pm SD ( $n=3$, technical replicates). Statistical analyses were performed using Student's $t$ test as ${ }^{* *} P<0.01$ and ${ }^{*} P<0.05$. Table S4. Wall polymer features in stems of transgenic lines and WT. Rha, Rhamnose; Fuc, Fucose; Ara, Arabinose; Xyl, Xylose; Man, Mannose; Gal, Galactose. Table S5. Characteristic peaks of the FTIR spectra in biomass residues as referred from previous studies. Table $\mathbf{S 6}$. Comparison of bioethanol yields obtained in the transgenic poplar plant and other woody plants. Fig. S1 Multiple sequence alignment and phylogenetic analysis of DET2. (a) The phylogenetic relationship of PtoDET2 with other DET2 proteins. (b) Sequence alignments of PtoDET2. The GenBank accession numbers of DET2s were listed in Table S1. Fig. S2 Generation of transgenic poplars. (a) Diagram of the PtoDET2-OE vector. (b) The Hyg levels in the PtoDET2OE lines. (c) The expression levels of PtoDET2 in the PtoDET2-OE lines. The poplar ubiquitin gene was used as an internal control. (d) Diagram of three CRISPR/Cas9 target sites of PtoDET2.T1,T2 and T3 indicate the positions of sgRNA-targeted sites. (e) Determination of the mutations in the coding region of PtoDET2 generated by the CRISPR/Cas9 system. The text on the right summarizes mutation details in two independent CRISPR/ Cas9-generated lines (L11 and L17). Primers are listed in Table S2. Fig. S3 Expression of cell differentiation, expansion and wall biosynthetic genes in PtoDET2 transgenic plants. (a) Cell differentiation genes; (b) cell expansion genes; (c) cellulose biosynthetic genes; (d) hemicellulose biosynthetic genes. Primers are listed in Table S2. The poplar ubiquitin gene was used as an internal control. All data are given as mean \pm SD from three biological repeats. Statistical analyses were performed using Student's $t$ test as ${ }^{* *} P<0.01$. Fig. $\mathbf{S 4}$ Hexoses released from enzymatic hydrolysis after various chemical pretreatments. (a) Hexose yields released from enzymatic (mixed-cellulase) hydrolysis after pretreatments with $\mathrm{H}_{2} \mathrm{SO}_{4}$, (b) $\mathrm{NaOH}$, (c) $\mathrm{CaO}$ or (d) $\mathrm{Na}_{2} \mathrm{~S}+\mathrm{Na}_{2} \mathrm{CO}_{3}$. All data are given as mean $\pm \mathrm{SD}$ of three technical repeats. Fig. S5 Expression of PtoGH9 genes in transgenic PtoDET2 plants. Primers are listed in Table S2 available as Supplementary Data. The poplar ubiquitin gene was used as an internal control. All data are given as mean \pm SD from three technical repeats. Statistical analyses were performed using Student's $t$ test as ${ }^{*} P<0.01$. Fig. S6 Mass balance analysis for bioethanol production during biomass process with green liquor in transgenic poplar lines and WT. Fig. S7 Fourier transform infrared spectra (FTIR) profiling in transgenic poplar lines and WT. Black line as raw material (R) and red line as biomass residue from $\mathrm{Na}_{2} \mathrm{~S}+\mathrm{Na}_{2} \mathrm{CO}_{3}$ pretreatment $(\mathrm{P})$. Characteristic peaks of the FTIR spectra were referred in Table S5. Fig. S8 A hypothetical model to demonstrate an integrated approach effective for maximum bioethanol production in lignocellulose-improved transgenic poplar plants overproducing BRs.

\section{Abbreviations}

DET2: DEETIOLATED2; BR: brassinosteroid; Crl: cellulose crystallinity index; DP degree of polymerization; Ara: arabinose; Xyl: xylose; SEM: scanning electron microscopy; CBH: cellobiohydrolase; Ph: phloem; C: cambium; Xy: xylem; Xf: xylem fiber cells; Xv: xylem vessel cells; P: pith; Ep: epidermis; GH: glycoside hydrolase; FTIR: Fourier transform infrared. 


\section{Authors' contributions}

CF completed major experiments and wrote the manuscript; HY participated in the $\mathrm{Na}_{2} \mathrm{~S}+\mathrm{Na}_{2} \mathrm{CO}_{3}$ pretreatment; $\mathrm{SQ}$, and $\mathrm{YL}$ participated in transgenic poplar plants collection; $\mathrm{AA}$ and $\mathrm{YW}$ participated in the cell wall determination; CX, DF, and QZ participated in the microscope observation; WZ participated in biomass porosity measurement; LP co-supervised experiments and interpreted data; KL supervised experiments and finalized the manuscript. All authors read and approved the final manuscript.

\section{Funding and acknowledgements}

This work was supported in part by grants from the National Science Foundation of China (31800505, 31870657, 31670669, 31870175), the Fundamental Research Funds for the Central Universities of China (XDJK2019C102), the China Postdoctoral Science Foundation (2018M643391, 2019T120802) and the Chongqing Postdoctoral Science Foundation (CQBX201701).

\section{Availability of data and materials}

All data generated or analyzed during this study are included in this published article and its additional file. Plant materials used in this study are available from corresponding author, Keming Luo (kemingl@swu.edu.cn).

\section{Ethics approval and consent to participate}

Not applicable.

\section{Consent for publication}

Upon request.

\section{Competing interests}

The authors declare that they have no competing interests.

\begin{abstract}
Author details
${ }^{1}$ Chongqing Key Laboratory of Plant Resource Conservation and Germplasm Innovation, Key Laboratory of Eco-environments of Three Gorges Reservoir Region, Ministry of Education, Institute of Resources Botany, School of Life Sciences, Southwest University, Chongqing 400715, China. ${ }^{2}$ Biomass \& Bioenergy Research Centre, College of Plant Science \& Technology, Huazhong Agricultural University, Wuhan 430070, China. ${ }^{3}$ College of Biomass Sciences and Engineering, College of Agronomy and Biotechnology, China Agricultural University, Beijing 100193, China.
\end{abstract}

Received: 6 November 2019 Accepted: 6 January 2020

Published online: 18 January 2020

\section{References}

1. Ragauskas AJ, Williams CK, Davison BH, Britovsek G, Cairney J, Eckert CA, Frederick WJ, Hallett JP, Leak DJ, Liotta CL, Mielenz JR, Murphy R, Templer $\mathrm{R}$, Tschaplinski T. The path forward for biofuels and biomaterials. Science. 2006;311(5760):484-9.

2. Service RF. Cellulosic ethanol-biofuel researchers prepare to reap a new harvest. Science. 2007;315(5818):1488-91.

3. Perlack RD, Wright LL, Turhollow A, Graham RL, Stokes B, Erbach DC. Biomass as feedstock for a bioenergy and bioproducts industry: the technical feasibility of a billion-ton annual supply. Oak Ridge: Oak Ridge National Laboratory; 2005.

4. Galbe M, Zacchi G. A review of the production of ethanol from softwood. Appl Microbiol Biotechnol. 2002;59(6):618-28.

5. Zhu JY, Pan XJ. Woody biomass pretreatment for cellulosic ethanol production: technology and energy consumption evaluation. Bioresour Technol. 2010;101(13):4992-5002.

6. Papari S, Hawboldt K. A review on the pyrolysis of woody biomass to biooil: focus on kinetic models. Renew Sustain Energy Rev. 2015;52:1580-95.

7. Pauly M, Keegstra K. Plant cell wall polymers as precursors for biofuels. Curr Opin Plant Biol. 2010;13(3):305-12.

8. Wang YT, Fan CF, Hu HZ, Li Y, Sun D, Wang YM, Peng LC. Genetic modification of plant cell walls to enhance biomass yield and biofuel production in bioenergy crops. Biotechnol Adv. 2016;34(5):997-1017.

9. Cheng SZ, Yu H, Hu M, Wu Y, Cheng LL, Cai QM, Tu YY, Xia T, Peng LC. Miscanthus accessions distinctively accumulate cadmium for largely enhanced biomass enzymatic saccharification by increasing hemicellulose and pectin and reducing cellulose $\mathrm{Cr}$ and DP. Bioresour Technol. 2018;263:67-74.

10. Hallac BB, Ragauskas AJ. Analyzing cellulose degree of polymerization and its relevancy to cellulosic ethanol. Biofuel Bioprod Biorefin. 2011;5(2):215-25.

11. Loque D, Scheller HV, Pauly M. Engineering of plant cell walls for enhanced biofuel production. Curr Opin Plant Biol. 2015;25:151-61.

12. Li FC, Zhang ML, Guo K, Hu Z, Zhang R, Feng YQ, Yi XY, Zou WH, Wang LQ, Wu CY, Tian JS, Lu TG, Xie GS, Peng LC. High-level hemicellulosic arabinose predominately affects lignocellulose crystallinity for genetically enhancing both plant lodging resistance and biomass enzymatic digestibility in rice mutants. Plant Biotechnol J. 2015;13(4):514-25.

13. Jin WX, Chen L, Hu M, Sun D, Li A, Li Y, Hu Z, Zhou SG, Tu YY, Xia T, Wang YT, Xie GS, Li YB, Bai BW, Peng LC. Tween-80 is effective for enhancing steam-exploded biomass enzymatic saccharification and ethanol production by specifically lessening cellulase absorption with lignin in common reed. Appl Energy. 2016;175:82-90.

14. Yarbrough JM, Mittal A, Mansfield E, Taylor LE, Hobdey SE, Sammond DW Bomble YJ, Crowley MF, Decker SR, Himmel ME, Vinzant TB. New perspective on glycoside hydrolase binding to lignin from pretreated corn stover. Biotechnol Biofuels. 2015;8(1):214

15. Cao S, Aita GM. Enzymatic hydrolysis and ethanol yields of combined surfactant and dilute ammonia treated sugarcane bagasse. Bioresour Technol. 2013;131:357-64.

16. Fan CF, Feng SQ, Huang JF, Wang YT, Wu LM, Li XK, Wang LQ, Tu YY, Xia T, Li JY, Cai XW, Peng LC. AtCesA8-driven OsSUS3 expression leads to largely enhanced biomass saccharification and lodging resistance by distinctively altering lignocellulose features in rice. Biotechnol Biofuels. 2017; 10:221.

17. Wu LM, Feng SQ, Deng J, Yu B, Wang YM, He BY, Peng H, Li Q, Hu RF, Peng LC. Altered carbon assimilation and cellulose accessibility to maximize bioethanol yield under low-cost biomass processing in corn brittle stalk. Green Chem. 2019;21:4388-99.

18. Li Y, Liu P, Huang JF, Zhang R, Hu Z, Feng SQ, Wang YT, Wang LQ, Xia T, Peng LC. Mild chemical pretreatments are sufficient for bioethanol production in transgenic rice straws overproducing glucosidase. Green Chem. 2018;20(9):2047-56.

19. Huang JF, Xia T, Li GH, Li XL, Li Y, Wang YT, Wang YM, Chen YY, Xie GS, Bai FW, Peng LC. Overproduction of native endo- $\beta-1,4$-glucanases leads to largely enhanced biomass saccharification and bioethanol production by specific modification of cellulose features in transgenic rice. Biotechnol Biofuels. 2019;12:11.

20. Fan C, Wang G, Wu L, Liu P, Huang J, Jin X, Zhang G, He Y, Peng L, Luo K, Feng S. Distinct cellulose and callose accumulation for enhanced bioethanol production and biotic stress resistance in OsSUS3 transgenic rice. Carbohyd Polym. 2019. https://doi.org/10.1016/j.carbpol.2019.115448.

21. Sindhu R, Binod P, Pandey A. Biological pretreatment of lignocellulosic biomass-an overview. Bioresour Technol. 2016;199:76-82.

22. Himmel ME, Ding SY, Johnson DK, Adney WS, Nimlos MR, Brady JW, Foust TD. Biomass recalcitrance: engineering plants and enzymes for biofuels production. Science. 2007;315(5813):804-7.

23. Pauly M, Keegstra K. Cell-wall carbohydrates and their modification as a resource for biofuels. Plant J. 2008:54(4):559-68.

24. Hu M, Yu H, Li Y, Li A, Cai QM, Liu P, Tu YY, Wang YT, Hu RF, Hao B, Peng $L C$, Xia T. Distinct polymer extraction and cellulose DP reduction for complete cellulose hydrolysis under mild chemical pretreatments in sugarcane. Carbohyd Polym. 2018;202:434-43.

25. Jin YC, Jameel H, Chang HM, Phillips R. Green liquor pretreatment of mixed hardwood for ethanol production in a repurposed kraft pulp mill. J Wood Chem Technol. 2010;30(1):86-104.

26. Kim JS, Lee YY, Kim TH. A review on alkaline pretreatment technology for bioconversion of lignocellulosic biomass. Bioresour Technol. 2016;199:42-8.

27. Saratale GD, Jung MY, Oh MK. Reutilization of green liquor chemicals for pretreatment of whole rice waste biomass and its application to 2,3-butanediol production. Bioresour Technol. 2016;205:90-6.

28. Gu F, Yang LF, Jin YC, Han Q, Chang HM, Jameel H, Phillips R. Green liquor pretreatment for improving enzymatic hydrolysis of corn stover. Bioresour Technol. 2012;124:299-305

29. Mood SH, Golfeshan AH, Tabatabaei M, Jouzani GS, Najafi G, Gholami M, Ardjmand M. Lignocellulosic biomass to bioethanol, a comprehensive 
review with a focus on pretreatment. Renew Sustain Energy Rev. 2013;27:77-93.

30. Růžička K, Ursache R, Hejátko J, Helariutta Y. Xylem development-from the cradle to the grave. New Phytol. 2015;207(3):519-35.

31. Ibañes M, Fàbregas N, Chory J, Caño-Delgado Al. Brassinosteroid signaling and auxin transport are required to establish the periodic pattern of Arabidopsis shoot vascular bundles. Proc Natl Acad Sci USA. 2009;106:13630-5.

32. Chung $Y$, Choe S. The regulation of brassinosteroid biosynthesis in Arabidopsis. Crit Rev Plant Sci. 2013;32(6):396-410.

33. Shen Y, Li YL, Xu D, Yang C, Li CF, Luo KM. Molecular cloning and characterization of a brassinosteroid biosynthesis-related gene PtoDWF4 from Populus tomentosa. Tree Physiol. 2018;38(9):1424-36.

34. Du J, Gerttula S, Li ZH, Zhao ST, Li-Liu Y, Liu Y, Lu MZ, Groover AT. Brassinosteroid regulation of wood formation in poplar. New Phytol. 2019. https://doi.org/10.1111/nph.15936.

35. Jin YL, Tang RJ, Wang HH, Jiang CM, Bao Y, Yang Y, Liang MX, Kong FJ, Li B, Zhang HX. Overexpression of Populus trichocarpa CYP85A3 promotes growth and biomass production in transgenic trees. Plant Biotechnol J. 2017;15(10):1309-21.

36. Jin H, Do J, Shin SJ, Choi JW, Choi YI, Kim W, Kwon M. Exogenously applied 24-epi brassinolide reduces lignification and alters cell wall carbohydrate biosynthesis in the secondary xylem of Liriodendron tulipifera. Phytochemistry. 2014;101:40-51.

37. Yamamoto R, Fujioka S, Demura T, Takatsuto S, Yoshida S, Fukuda H. Brassinosteroid levels increase drastically prior to morphogenesis of tracheary elements. Plant Physiol. 2001;125(2):556-63.

38. Yamamoto R, Fujioka S, I wamoto K, Demura T, Takatsuto S, Yoshida S, Fukuda H. Co-regulation of brassinosteroid biosynthesis-related genes during xylem cell differentiation. Plant Cell Physiol. 2007;48(1):74-83.

39. He JX, Gendron JM, Sun Y, Gampala SSL, Gendron N, Sun CQ, Wang ZY. BZR1 is a transcriptional repressor with dual roles in brassinosteroid homeostasis and growth responses. Science. 2005;307(5715):1634-8.

40. He K, Gou XP, Yuan T, Lin HH, Asami T, Yoshida S, Russell SD, Li J. BAK1 and BKK1 regulate brassinosteroid-dependent growth and brassinosteroid independent cell-death pathways. Curr Biol. 2007:17(13):1 109-15.

41. Yu LL, Sun JY, Li LG. PtrCel9A6, an endo-1,4-glucanase, is required for cell wall formation during xylem differentiation in Populus. Mol Plant. 2013;6(6):1904-17.

42. Xie GS, Yang B, Xu ZD, Li FC, Guo K, Zhang ML, Wang LQ, Zou WH, Wang YT, Peng LC. Global identification of multiple OsGH9 family members and their involvement in cellulose crystallinity modification in rice. PLOS ONE. 2013;8(1):e50171.

43. Li Y, Sun HY, Fan CF, Hu HZ, Jin XH, Lv ZY, Wang YT, Feng SQ, Chen P, Peng LC. Overproduction of fungal endo-b-1,4-glucanase leads to characteristic lignocellulose modification for considerably enhanced biomass enzymatic saccharification and bioethanol production in transgenic rice straw. Cellulose. 2019;26:8249-61.

44. Wiman M, Dienes D, Hansen MAT, van der Meulen T, Zacchi G, Liden G. Cellulose accessibility determines the rate of enzymatic hydrolysis of steam-pretreated spruce. Bioresour Technol. 2012;126:208-15.

45. Alam A, Zhang R, Liu P, Huang JF, Wang YT, Hu Z, Madadi M, Sun D, Hu RF, Ragauskas AJ, Tu YY, Peng LC. A finalized determinant for complete lignocellulose enzymatic saccharification potential to maximize bioethanol production in bioenergy Miscanthus. Biotechnol Biofuels. 2019;1 2:99.

46. Fujioka S, Li J, Choi YH, Seto H, Takatsuto S, Noguchi T, Watanabe T, Kuriyama H, Yokota T, Chory J, Sakurai A. The Arabidopsis deetiolated2 mutant is blocked early in brassinosteroid biosynthesis. Plant Cell. 1997:9:1951-62.

47. Nomura T, Jager CE, Kitasaka Y, Takeuchi K, Fukami M, Yoneyama K, Matsushita Y, Nyunoya H, Takatsuto S, Fujioka S, Smith JJ, Kerckhoffs LH, Reid JB, Yokota T. Brassinosteroid deficiency due to truncated steroid 5alpha-reductase causes dwarfism in the Ik mutant of pea. Plant Physiol. 2004;135:2220-9.

48. Xie L, Yang C, Wang X. Brassinosteroids can regulate cellulose biosynthesis by controlling the expression of CESA genes in Arabidopsis. J Exp Bot. 2011;62(13):4495-506
49. Boerjan W, Ralph J, Baucher M. Lignin biosynthesis. Annu Rev Plant Biol. 2003;54:519-46.

50. Bonawitz ND, Chapple C. The genetics of lignin biosynthesis: connecting genotype to phenotype. Annu Rev Genet. 2010;44:337-63.

51. Cheng LL, Wang LQ, Wei LY, Wu Y, Alam A, Xu CB, Wang YT, Tu YY, Peng $L C$, Xia T. Combined mild chemical pretreatments for complete cadmium release and cellulosic ethanol co-production distinctive in wheat mutant straw. Green Chem. 2019;21(13):3693-700.

52. Biswal AK, Atmodjo MA, Li M, Baxter HL, Yoo CG, Pu Y, Lee Y, Mazarei M, Black LM, Zhang JY, Ramanna H, Bray AL, King ZR, LaFayette P, Pattathil S, Donohoe BS, Mohanty SS, Ryno D, Yee K, Thompson OA, Rodriguez M, Dumitrache A, Natzke J, Winkeler K, Collins C, Yang XH, Tan L, Sykes RW, Gjersing EL, Ziebell A, Turner GB, Decker SR, Hahn MG, Davison BH, Udvardi MK, Mielenz JR, Davis MF, Nelson RS, Parrott WA, Ragauskas AJ, Stewart CN, Mohnen D. Sugar release and growth of biofuel crops are improved by downregulation of pectin biosynthesis. Nat Biotechnol. 2018;36(3):249.

53. Cai YH, Zhang KW, Kim H, Hou GC, Zhang XB, Yang HJ, Feng H, Miller L, Ralph J, Liu CJ. Enhancing digestibility and ethanol yield of Populus wood via expression of an engineered monolignol 4-O-methyltransferase. Nat Commun. 2016;7:11989.

54. Ko CH, Wang YN, Chang FC, Chen JJ, Chen WH, Hwang WS. Potentials of lignocellulosic bioethanols produced from hardwood in Taiwan. Energy. 2012:44:329-34.

55. Romani A, Garrote G, Ballesteros I, Ballesteros M. Second generation bioethanol from steam exploded Eucalyptus globulus wood. Fuel. 2013;111:66-74.

56. Cara C, Ruiz E, Ballesteros M, Manzanares P, Negro MJ, Castro E. Production of fuel ethanol from steam-explosion pretreated olive tree pruning Fuel. 2008;87:692-700.

57. Fan D, LiuT, Li C, Jiao B, Li S, Hou Y, Luo K. Efficient CRISPR/Cas9-mediated targeted mutagenesis in Populus in the first generation. Sci Rep. 2015;5:12217.

58. Jia ZC, Sun YM, Yuan L, Tian QY, Luo KM. Immunophilin FK506 loaded in chitosan guide promotes peripheral nerve regeneration. Biotechnol Lett. 2010;32:1325-32.

59. Scott F, Venturini F, Aroca G, Conejeros R. Selection of process alternatives for lignocellulosic bioethanol production using a MILP approach. Bioresour Technol. 2013;148:525-34.

60. Peng LC, Hocart CH, Redmond JW, Williamson RE. Fractionation of carbohydrates in Arabidopsis root cell walls shows that three radial swelling loci are specifically involved in cellulose production. Planta. 2000;211:406-14.

61. Fan CF, Li Y, Hu Z, Hu HZ, Wang GY, Li A, Wang YM, Tu YY, Xia T, Peng LC, Feng SQ. Ectopic expression of a novel OsExtensin-like gene consistently enhances plant lodging resistance by regulating cell elongation and cell wall thickening in rice. Plant Biotechnol J. 2018;16:254-63.

62. Sluiter A, Hames B, Ruiz R, Scarlata C, Sluiter J, Templeton D, Crocker D. Determination of structural carbohydrates and lignin in biomass. Lab Anal proced. 2008;1617:1-16

63. Lapierre C, Pollet B, Rolando C. New insights into the molecular architecture of hardwood lignins by chemical degradative methods. Res Chem Intermed. 1995;21:397.

64. Brunauer S, Emmett PH, Teller E. Adsorption of gases in multimolecular layers. J Am Chem Soc. 1938;60:309-19.

65. LiuTY, Ma Y, Yu SF, Shi J, Xue S. The effect of ball milling treatment on structure and porosity of maize starch granule. Innov Food Sci Emerg. 2011;12(4):586-93.

\section{Publisher's Note}

Springer Nature remains neutral with regard to jurisdictional claims in published maps and institutional affiliations. 